Õber die fermentative Hydroperoxydzersetzung.

\author{
III. Mitteilung. \\ Von \\ Percy Waentig und Otto Steche.
}

(Mitteilung aus dem Laboratorium für angewandte Chemie der Universität Leipzig.)

(Der Redaktion zugegangen am 15. Juni 1912.)

\title{
Einleitung.
}

In dieser Mitteilung soll auf einen Punkt näher eingegangen werden, der schon in der vorangegangenen Arbeit erwähnt, jedoch nicht ausführlich erörtert werden konnte, nämlich die Frage, inwieweit sich die fermentative Hydroperoxydzersetzung dem Schema einer Reaktion erster Ordnung anpaßt. Daß dies der Fall sei, ist bekanntlich von Senter ${ }^{1}$ ) hervorgehoben und auf Grund der Arbeiten von Senter und Euler') trotz einiger entgegengesetzter Befunde anderer Autoren auch in zusammenfassende Darstellungen ${ }^{3}$ ) über die Fermente übergegangen. Kürzlich ${ }^{4}$ ) hat nun Senter die in unserer ersten Mitteilung auf Grund unserer experimentellen Erfahrungen ausgesprochenen Zweifel hieran als unbegründet zurückweisen zu müssen geglaubt. Denn obgleich auch er unter gewissen Bedingungen Abweichungen vom normalen Schema beobachten konnte, glaubte er doch, diese durch die Annahme gewisser Nebenerscheinungen erklären zu können, die er zum Teil experimentell zu beweisen, zum anderen Teil gelegentlich einer Diskussion mit Sand ${ }^{5}$ ) wahrscheinlich zu machen sich bemüht hat.

Unsere Zweifel an der Richtigkeit der Auffassung Senters gründeten sich darauf, daß wir unter den nach Senter für einen normalen Reaktionsverlauf ausreichenden Bedingungen eine Reaktion erster Ordnung nicht beobachten konnten und auch die von Senter vermuteten Ursachen für die von ihm selbst beobachteten Abweichungen als für die von uns

1) Diese Zeitschrift, Bd. 44, S. 317 f. (1903).

2) Hofmeisters Beiträge 1906, Bd. 1, S. 1.

s) Vgl. H. Euler, Allgemeine Chemie des Enzyms. Wiesbaden 1910. C. Oppenheimer, Die Fermente (1909) I, S. 402 (III. Aufl.).

H. Freundlich, Kapillarchemie 1909.

4) Diese Zeitschrift, Bd. 74, S. 101 (1911).

5) Diese Zeitschrift, Bd. 52, S. 737 (1905). 
untersuchten Fälle nicht in Betracht kommend erkannt hatten. Wir mußten danach den monomolekularen Reaktionsverlauf als einen mehr zufälligen ansehen.

Diesen Standpunkt glaubten wir um so eher einnehmen zu dürfen, als sich bei näherer Prüfung die Annahme Senters über die Natur der gemessenen Reaktion als eines reinen Diffusionsvorganges im mikroheterogenen System, ferner seine Annahmen für die Ursachen der Abweichungen davon (Oxydation des Ferments, Bildung von Gasbläschen an der Oberfläche des Colloids, Rührwirkung der Sauerstoffbläschen) sich in vieler Beziehung nicht mit unseren eigenen Versuchen in Einklang bringen ließen.

Aber wir haben uns in unseren früheren Mitteilungen absichtlich nicht auf theoretische Fragen eingelassen und uns damit begnügt, darauf hinzuweisen, daß die von Senter verlangten Bedingungen für einen normalen Reaktionsverlauf zum mindesten ungenügend seien. Unsere zweite Mitteilung, in der wir außer der Hämase andere Katalasen in den Kreis der Betrachtung gezogen haben, hat diese Auffassung durchaus bestätigt, obwohl wir im allgemeinen Verhalten dieser Fermente keine prinzipiellen Unterschiede feststellen zu können glaubten, die auf eine stoffliche Verschiedenheit der Katalaselösungen verschiedener Herkunft hätte schließen lassen.

Die Ansicht Senters konnten wir daher nicht teilen, daß der bloße Nachweis einer irreversiblen Zerstörung des Ferments während der Reaktion ausreiche, die Richtigkeit seiner Annahmen zu bestätigen. Vielmehr war es erforderlich, die Richtigkeit der Diffusions- und Oxydationshypothese mit den daraus gezogenen, für ein mikroheterogenes System in Betracht kommenden Konsequenzen möglichst eingehend zu prüfen. Das Ergebnis dieser Prüfung, zu der außer der Blutfermentlösung auch eine Reihe anderer Fermentlösungen herangezogen wurden, soll im folgenden dargelegt werden.

\section{Die Oxydationshypothese.}

Der wichtigste Punkt, um dies nochmals zu betonen, der uns zu dem oben dargelegten abweichenden Schluß geführt 
hatte, war der, daß, während Senter bei keinem der zahlreichen von ihm mitgeteilten Versuche einen absteigenden Gang in den K-Werten unter Normalbedingungen erhielt, wir sehr häufig einen solchen beobachteten. Senter hat in seiner Erwiderung erklärt, daß dieser Gang nur bei einigen unserer Fermentlösungen aufgetreten sei und deshalb durch eine zufällig vorhandene mehr oder weniger starke Oxydierbarkeit des Fermentes erklärt werden könne.

Im folgenden soll zunächst gezeigt werden, daß auch bei Fermenten aus ein und derselben Probe Blut, ja sogar bei ein und derselben Fermentlösung der Gang auftreten oder fehlen kann, und daß der Gang aus diesem Grunde und einer Anzahl anderer durch einen Oxydationsvorgang nicht veranlaßt sein kann. Um hierzu uns möglichst den Senterschen Versuchsanordnungen anzupassen, haben wir den Reaktionsverlauf nicht nur so lange beobachtet, bis das Peroxyd in dem Reaktionsgemisch verbraucht war, sondern wir haben auch die Reaktion mit solchen Fermenten verfolgt, die bereits Hydroperoxyd in größerer Menge zersetzt hatten. Dies konnte auf doppelte Weise erreicht werden. Entweder, wie Senter selbst ausgeführt und vorgeschlagen hat, in der Weise, daß wir mehrere Fermentlösungen gleicher Konzentration herstellten und in sämtlichen Gemischen durch gleichzeitigen Hydroperoxydzusatz die Reaktion einleiteten, die zum Verfolg des Reaktionsverlaufs erforderlichen Entnahmen jedoch nur in einem der Gemische vornahmen, während die anderen sich selbst überlassen blieben, bis die Hydroperoxydkonzentration auf einen kleinen Betrag heruntergegangen war. Darauf wurde wieder in die noch unberührten Kölbchen die gleiche Peroxydmenge gebracht und wieder nur eins der noch übrigen Kölbchen zu Entnahmezwecken verwendet u.s.f. Auf diese Weise konnten also die Fermentlösungen untersucht werden, nachdem sie die ein-, zwei-, drei- und mehrfache Menge Peroxyd zersetzt hatten, ohne daß die Peroxydkonzentration in einem Reaktionsgemisch über den anfänglichen Betrag steigen konnte. Ein Mangel dieser Methode liegt darin, daß man in Wahrheit nicht immer ein und dieselbe Fermentlösung, sondern verschiedene untersucht, die nur den gleichen Bedingungen 
unterliegen. Sicherer ist es daher, um aus derartigen «Dauerversuchen» einwandfreie Schlüsse zu ziehen, so zu verfahren, daß man eine möglichst große Menge Fermentlösung in Reaktion bringt und nach Verbrauch einer bestimmten Menge Peroxyd in derselben das Peroxyd in eben dieser Fermentlösung nach Maßgabe des durch die Titrationsentnahmen erfolgten Verlustes an Gesamtreaktionsflüssigkeit erneuert. In dieser Weise wurde die Mehrzahl der im Nachstehenden mitgeteilten Versuche ausgeführt. ${ }^{1}$ )

Die Fermentlösungen waren in der üblichen, früher beschriebenen Weise hergestellt, indem die Alkoholfällungen nach Auswaschen und Trocknen mit einer bestimmten Wassermenge extrahiert und darauf die Extrakte vom Niederschlag abfiltriert und in geeigneter Weise verdünnt wurden. Wie nun die Versuche zeigen, tritt wieder in einer großen Zahl der Fälle ein Gang der K-Werte auf. (Tab. 1.) Wäre dieser Gang, wie Senter meint, durch Oxydation veranlaßt, so müßte man erwarten, daß eine Verringerung der Peroxydkonzentration eine Besserung des Ganges hervorrufe, daß ferner Erhöhung der Temperatur den Gang vergrößere, daß die durch die Oxydation verursachte Fermentschwächung bei jedem neuen Peroxydzusatz von neuem eintrete, und daß die Schwächung endlich, wenn einmal bei einer Fermentlösung beobachtet, jedesmal von neuem wieder auftrete, wenn die Fermentlösung unter den gleichen Bedingungen zur Reaktion gebracht wird. Von alledem ist jedoch nichts zu beobachten, häufig ist das Gegenteil der Fall. Erhöhung der Reaktionstemperatur auf $20^{\circ}$ verstärkt den Gang nicht, wie zu erwarten wäre, wenn eine Oxydation vorläge; sondern im Gegenteil der Gang wird kleiner. (Tab. 2.) Es ist darauf hinzuweisen, daß dies in einer sehr großen Zahl von Fällen festgestellt wurde, deren Anführung hat unterbleiben müssen. In vielen Fällen ist sogar bei $20^{\circ}$ eine Zunahme der

1) In den Versuchstabellen sind die verschiedenen Versuchsanordnungen dadurch kenntlich gemacht, daß ein erneuter Peroxydzusatz zum gleichen Reaktionsgemisch durch eine römische Ziffer hervorgehoben ist. Bei Untersuchung mehrerer Reaktionsgemische nacheinander ist dies durch die Bezeichnung I. Lösung, II. Lösung usw. angedeutet. 
Tabelle 1. Charakteristische Unregelmäßigkeiten im Reaktionsverlauf bei langer Versuchsdauer.

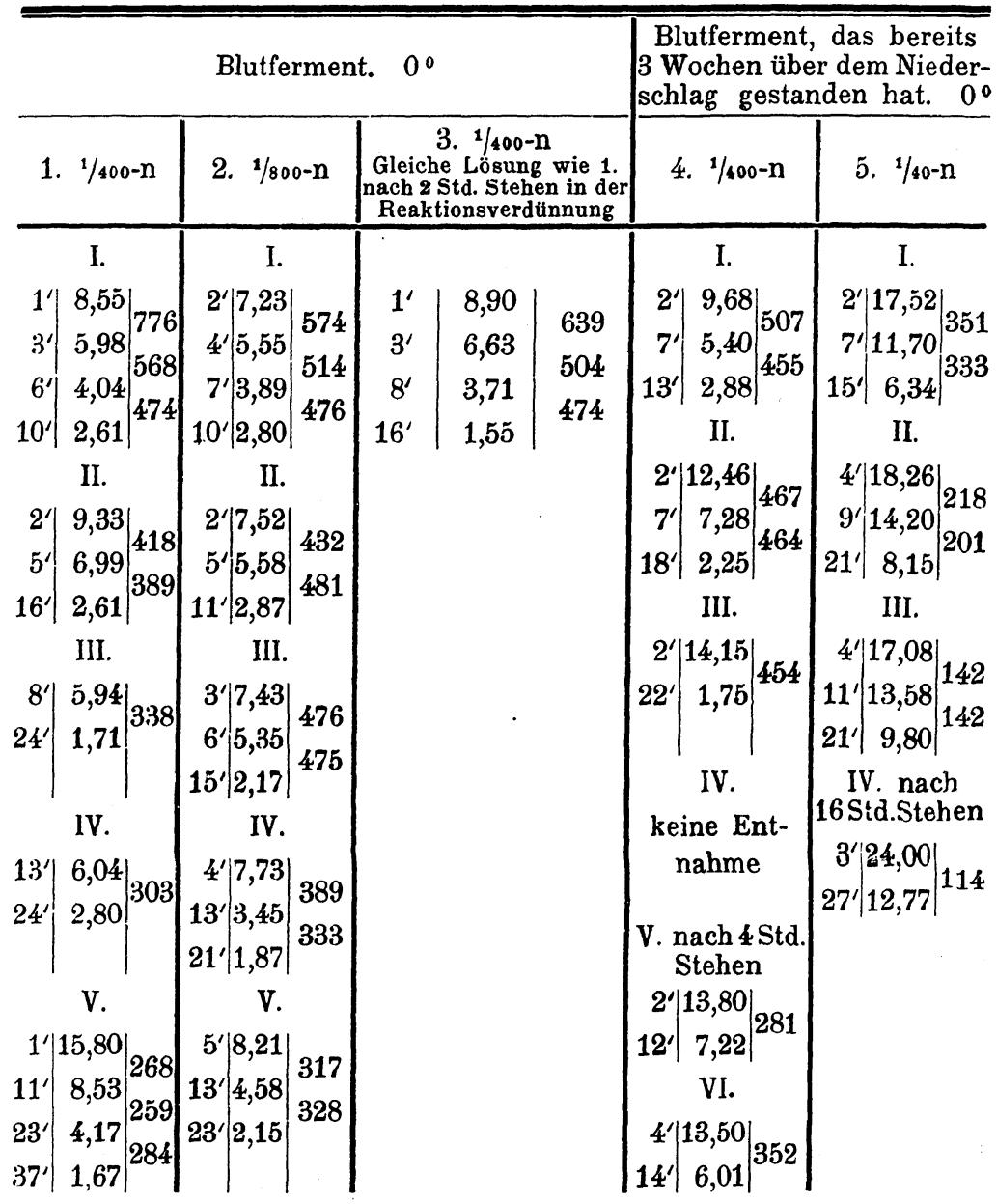

K-Werte im Verlauf der Reaktion festzustellen, während bei $0^{0}$ ein deutlicher Gang nach abwärts für die gleiche Fermentlösung beobachtet wird. Man kann ferner die Hydroperoxydkonzentration von $1 / 400$ auf $1 / 80 \mathrm{n}$. bei $0^{\circ}$, also um das 5 fache erhöhen, ohne daß eine merkliche Änderung des Ganges zu beobachten ist, während sich doch die oxydierende Wirkung, wenn eine solche vorhanden wäre, verstärken müßte. Die 
einzige Wirkung erhöhter Peroxydkonzentration etwa von 1/80 $\mathrm{n}$. an besteht darin, daß die Reaktionsgeschwindigkeit insgesamt etwas geringer ist (vgl. Tab. 3 u. 5).

Tabelle 2. Einfluß der Temperatur auf den Reaktionsverlauf.

\begin{tabular}{|c|c|c|c|c|c|c|c|c|c|}
\hline & \multicolumn{3}{|c|}{$\begin{array}{l}\text { 1. Blutferment, } \\
\text { Alkoholfällung }\end{array}$} & \multicolumn{3}{|c|}{ 2. gleiches Ferment } & \multicolumn{3}{|c|}{$\begin{array}{l}\text { 3. Blutferment, } \\
\text { II. Alkoholfällung }\end{array}$} \\
\hline $0^{0}$ & $\begin{array}{r}2^{\prime} \\
5^{\prime} \\
6^{\prime} \\
7^{\prime} \\
11^{\prime}\end{array}$ & $\begin{array}{r}19,53 \\
10,68 \\
8,57 \\
7,15 \\
3,58\end{array}$ & $\begin{array}{l}979 \\
956 \\
787 \\
751\end{array}$ & $\begin{array}{c}2^{\prime} \\
4^{\prime} \\
6^{\prime} \\
10^{\prime}\end{array}$ & $\begin{array}{r}20,92 \\
15,67 \\
12,24 \\
8,10\end{array}$ & $\begin{array}{l}628 \\
537 \\
448\end{array}$ & $\begin{array}{r}2^{\prime} \\
4^{\prime} \\
6^{\prime} \\
8^{\prime} \\
10^{\prime} \\
12^{\prime} \\
16^{\prime} \\
\end{array}$ & $\begin{array}{r}22,66 \\
16,80 \\
13,53 \\
11,01 \\
9,44 \\
8,17 \\
6,08 \\
\end{array}$ & $\begin{array}{l}650 \\
470 \\
498 \\
334 \\
314 \\
321\end{array}$ \\
\hline $20^{\circ}$ & $\begin{array}{l}2^{\prime} \\
3^{\prime} \\
4^{\prime} \\
5^{\prime} \\
6^{\prime} \\
7^{\prime} \\
9^{\prime}\end{array}$ & $\begin{array}{r}17,04 \\
13,24 \\
10,19 \\
7,68 \\
5,69 \\
4,12 \\
2,32\end{array}$ & $\begin{array}{l}1096 \\
1137 \\
1228 \\
1303 \\
1423 \\
1237\end{array}$ & $\begin{array}{c}2^{\prime} \\
4^{\prime} \\
6^{\prime} \\
8^{\prime} \\
10^{\prime}\end{array}$ & $\begin{array}{r}20,34 \\
14,57 \\
9,50 \\
6,89 \\
4,60\end{array}$ & $\begin{array}{l}723 \\
797 \\
840 \\
877\end{array}$ & $\begin{array}{c}2^{\prime} \\
4^{\prime} \\
6^{\prime} \\
8^{\prime} \\
10^{\prime}\end{array}$ & $\begin{array}{r}19,40 \\
11,58 \\
6,80 \\
4,19 \\
2,50\end{array}$ & $\begin{array}{l}1121 \\
1156 \\
1052 \\
1121\end{array}$ \\
\hline
\end{tabular}

Ebenso spricht die Art und Weise der Aktivitätsänderung des Ferments während der Reaktion gegen eine Oxydation. Wenn eine solche vorläge, sollte man annehmen, daß sie, wie gesagt, nach Maßgabe der jeweiligen Hydroperoxydkonzentrationen erfolgen müsse, d. h. zunächst erheblich wäre und dann schwächer würde, und daß bei mehrmaligem Hydroperoxydzusatz dieses Spiel sich stets wiederholte. Dies ist nicht der Fall, sondern man kann auch bei ein und derselben Fermentlösung alle möglichen Arten des Abfalls beobachten: z. B. sprungweises Abfallen der $\mathrm{K}$-Werte in den ersten Phasen der Reaktion, dann Konstanz, oder auch allmählichen, ziemlich gleichmäßigen Abfall. Bei Versuchen mit mehrmaligem Hydroperoxydzusatz ist sehr häufig ein schließliches Konstantwerden der K-Werte zu beobachten,. was nach der Oxydationstheorie ebenfalls nicht erklärlich wäre, Alles dies kann, wie gesagt, bei ein und der- 
Tabelle 3. Einfluß der $\mathrm{H}_{2} \mathrm{O}_{2}$-Konzentration auf den Reaktionsverlauf.

Blutferment.

\begin{tabular}{|c|c|c|c|c|c|c|c|c|c|}
\hline & \multicolumn{3}{|c|}{ 1. $1 / 400-n-H_{2} O_{2}$} & \multicolumn{3}{|c|}{ 2. ${ }^{1} / 80-n-H_{2} \mathrm{O}_{2}$} & \multicolumn{3}{|c|}{$\begin{array}{l}\text { 3. } 1 / 80-n-\mathrm{H}_{2} \mathrm{O}_{2} \\
\text { Parallelversuch }\end{array}$} \\
\hline $0^{\circ}$ & $\begin{array}{r}2^{\prime} \\
4^{\prime} \\
8^{\prime} \\
13^{\prime} \\
\\
2^{\prime} \\
6^{\prime} \\
12^{\prime}\end{array}$ & $\begin{array}{c}\text { I. } \\
10,51 \\
7,20 \\
3,81 \\
1,80 \\
\text { II. } \\
17,55 \\
10,33 \\
4,68\end{array}$ & $\begin{array}{l}807 \\
691 \\
651\end{array}$ & $\begin{array}{r}1^{\prime} \\
4^{\prime} \\
6^{\prime} \\
10^{\prime} \\
\\
1^{\prime} \\
4^{\prime} \\
7^{\prime} \\
11^{\prime}\end{array}$ & \begin{tabular}{|c|} 
I. \\
15,69 \\
9,89 \\
7,04 \\
3,65 \\
II. \\
16,15 \\
11,05 \\
7,64 \\
4,70
\end{tabular} & $\begin{array}{l}549 \\
521 \\
527\end{array}$ & $\begin{array}{r}1^{\prime} \\
4^{\prime} \\
6^{\prime} \\
10^{\prime}\end{array}$ & $\mid \begin{array}{r}17,55 \\
10,20 \\
7,61 \\
4,25\end{array}$ & $\begin{array}{l}786 \\
636 \\
633\end{array}$ \\
\hline $20^{\circ}$ & $\begin{array}{r}2^{\prime} \\
4^{\prime} \\
8^{\prime} \\
12^{\prime} \\
\\
1^{\prime} \\
5^{\prime} \\
10^{\prime}\end{array}$ & $\begin{array}{c}\text { I. } \\
10,64 \\
6,75 \\
2,69 \\
1,06 \\
\text { II. } \\
15,25 \\
5,98 \\
1,50\end{array}$ & $\begin{array}{r}988 \\
999 \\
1011\end{array}$ & $\begin{array}{r}1^{\prime} \\
3^{\prime} \\
5^{\prime} \\
9^{\prime} \\
\\
1^{\prime} \\
3^{\prime} \\
5^{\prime} \\
11^{\prime} \\
\\
1^{\prime} \\
3^{\prime} \\
5^{\prime} \\
11^{\prime}\end{array}$ & \begin{tabular}{|c} 
I. \\
15,10 \\
9,70 \\
6,15 \\
2,55 \\
II. \\
15,06 \\
10,15 \\
7,15 \\
2,80 \\
III. \\
14,70 \\
11,35 \\
9,10 \\
4,68
\end{tabular} & $\begin{array}{l}857 \\
760 \\
679 \\
\\
562 \\
480 \\
481\end{array}$ & & & \\
\hline
\end{tabular}

selben Fermentlösung bei verschiedenen Versuchen unter sonst völlig gleichen Reaktionsbedingungen beobachtet werden. Das Auffälligste jedoch ist, daß der eben untersuchte Gang bei gewissen Versuchen überhaupt auch ganz ausbleiben kann (cf. Tab. 1).

Dem Anschein nach ist also die Art des Reaktionsverlaufs 
völlig zufällig. Jedenfalls ist sie durch einen Oxydationsvorgang nicht $\mathrm{zu}$ erklären, wenn man nicht annehmen will, daß dieser mit ganz unbestimmbar wechselnder Geschwindigkeit eintritt und manchmal aus ebenso unerklärlichen Gründen überhaupt ausbleibt.

Man kann erst einen gewissen Aufschluß über die diesen anscheinend regellosen Erscheinungen zugrunde liegenden Ursachen gewinnen, wenn man die absoluten Beträge der $\mathrm{K}$-Werte von einem zum anderen Versuch vergleicht. Da zeigt sich nämlich, daß diese keineswegs immer gleich sind, und daß unter sonst gleichen Reaktionsbedingungen häufig diejenigen Versuche die besseren Konstanten liefern, deren Reaktionsgeschwindigkeit im ganzen geringer ist. Wenn man nun die in Tabelle 4 und 6 mitgeteilten Versuche betrachtet, in denen das Alter der Fermentlösung vom Zeitpunkt der Filtration an angegeben ist, so gewinnt man den Eindruck, daß der mit dem Altern der Fermentlösungen verknüpfte Aktivitätsrückgang mit der besseren Konstanz im Zusammenhang steht, daß also der Vorgang, der in der abfiltrierten Lösung nach Tagen von selbst zu einem/ gewissen Aktivitätsrückgange des Ferments führt, bei der frischen Lösung durch die Reaktion selbst in kurzer Zeit hervorgebracht wird und den Gang der K-Werte dadurch bedingt.

Als Ursache für diese Beschleunigung des Aktivitätsrückganges im Reaktionsgemisch lag es nahe, an eine Verdünnungswirkung zu denken, umsomehr, als schon früher etwas Ähnliches von uns festgestellt wurde, bei Versuchen, in denen wir den Einfluß der Mischungsbedingungen prüften (vgl. I. Mitteilung, S. 256), und da anderseits häufig Verdünnungstrübungen festgestellt wurden. Erneute Versuche in dieser Richtung haben nun auch ergeben, daß eine solche Wirkung vorliegt: Läßt man nämlich von zwei Fermentlösungen, die eine gewisse Zeit in der Reaktionsverdünnung stehen, so findet man bei einem Vergleich der Reaktion in den beiden Gemischen, daß die sogleich untersuchte Fermentlösung höhere Anfangs-K-Werte und einen stärkeren Gang derselben aufweist, als die Lösung, die eine Zeitlang gestanden hat, wie das auch schon in unserer ersten Mitteilung dargelegt wurde. Jedoch kann diese Erscheinung den Gang nicht vollständig er-

Huppe-Seyler's Zeitsehrift f. physiol. Chemie. LXXIX. 
Tabelle 4. Einfluß des Alters der Fermentlösung auf den Reaktionsverlauf.

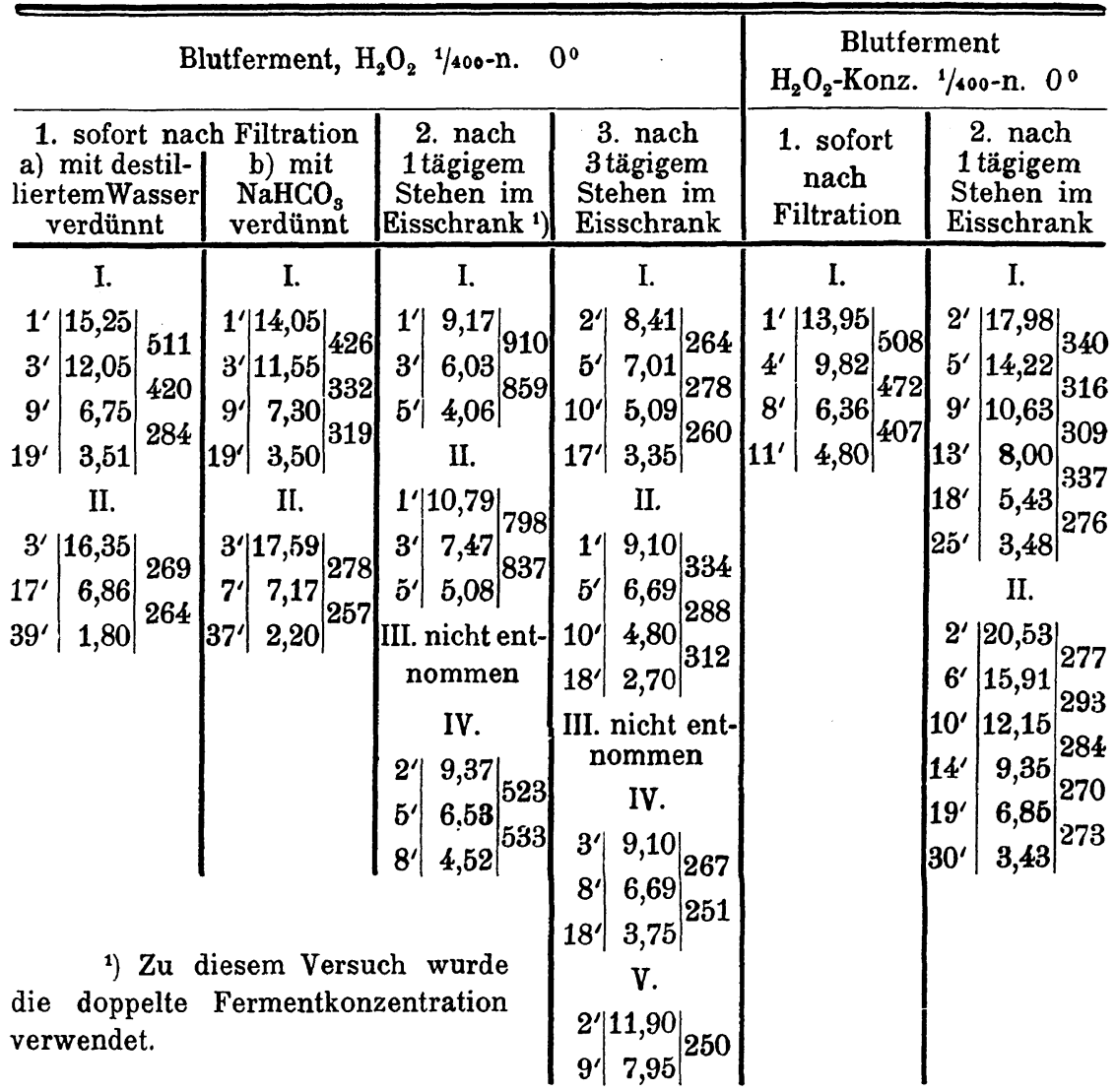

klären. Denn diese Verdünnungswirkung erfolgt, wie sich leicht zeigen läßt, viel langsamer, als aus dem Gang der K-Werte während der Reaktion zu schließen wäre. Ebensowenig besteht ein Zusammenhang zwischen der durch die Verdünnung veranlaßten sichtbaren Trübung und dieser Aktivitätsabnahme einerseits und dem Gang der K-Werte anderseits. Dies folgt aus Versuchen mit Blutalkoholfällungen, die mit verdünnter $\mathrm{Bi}$ carbonatlösung statt mit destilliertem Wasser extrahiert wurden. Derartige Lösungen, welche ja nur ganz schwach alkalisch reagieren, sodaß also ihr Hydroxyl- und Wasserstoffionengleich- 
gewicht nicht wesentlich verändert ist, trüben sich nämlich nicht beim Verdünnen. Den Gang der K-Werte bei der Reaktion liefern sie jedoch in ganz der gleichen Weise.

Immerhin schien die Verdünnung nach den eben beschriebenen Versuchen doch nicht ganz ohne Einfluß. Da zu den Verdünnungszwecken kohlensäurehaltiges Wasser verwendet war, so lag es nahe, die Versuche mit kohlensäurefreiem Wasser zu wiederholen. Der Versuch ergab keine Verdünnungswirkung bei den auf diese Weise hergestellten Lösungen. Es war also damit jedenfalls diese Wirkung auf eine Schwächung durch den Kohlensäuregehalt destillierten Wassers zurückgeführt worden.

Nach alledem muß man also annehmen, daß das Peroxyd selbst sich in irgend einer noch ungeklärten Weise an dem Aktivitätsrückgange der Fermentlösung beteiligt, der auch durch Verdünnung der Fermentlösung mit kohlensäurehaltigem Wasser, wenn auch in viel geringerem Betrage, auftreten kann.

Daß die Aktivitätsabnahme durch Altern der Fermentlösung mit dem Gang bei frischen Fermentlösungen im $\mathrm{Zu}$ sammenhang steht, wird noch besonders wahrscheinlich durch einen Vergleich derjenigen K-Werte, welche ein durch Altern konstant gewordenes Ferment ergibt, mit denjenigen, welche das gleiche noch frische Ferment lieferte, nachdem das Peroxyd einige Zeit eingewirkt hat. Bei $0^{\circ}$ und nicht zu hoher Peroxydkonzentration ist es die Regel, daß der Abfall der Fermentaktivität, gemessen an den K-Werten, so vor sich geht, daß er anfänglich stark ist, um allmählich unabhängig von der Peroxydkonzentration im Reaktionsgemisch entweder ganz zu verschwinden oder wenigstens einen ziemlich gleichmäßigen Verlauf anzunehmen. Vergleicht man nun die K-Werte einer frischen Fermentlösung in diesem Stadium der Reaktion mit den K-Werten, die unter den gleichen Reaktionsbedingungen das gealterte Ferment anfänglich liefert, so ergibt sich, daß die Werte sich etwa auf gleicher Höhe befinden (vgl. Tab. 4 u. 6).

Anderseits ist $\mathrm{zu}$ betonen, daß, wie das schon in unserer I. Mitteilung dargelegt worden ist, der Gang nicht bei allen Fermentlösungen auftritt, sondern daß es Extrakte gibt, die von 
vornherein konstante $\mathrm{K}$-Werte zeigen und dann auch diese Konstanz beim Altern der Fermentlösung uuverändert beibehalten (vgl. hierüber die Angaben in unserer I. Mitteilung). Dies macht natürlich das Experimentieren mit derartigen Extrakten sehr mühsam. Denn man kann nie von vornherein sagen, ob eine Alkoholfällung Extrakte liefern wird, welche Konstanz zeigen oder nicht. Ebensowenig läßt sich etwas Sicheres über die Wirkung des Alterns bei einer Fermentlösung mit Gang sagen:

Der Gang verschwindet also bei älteren Fermentlösungen häufig, wobei gleichzeitig die gesamte Aktivität zurückgeht. Aber es ist dies keine ausnahmslose Regel. Findet jedoch ein Rückgang der Aktivität statt, so verringert sich der Gang unter allen Umständen. Auch der Gang selbst ist, wie schon betont wurde, nicht immer in Parallelversuchen völlig gleich. Der Abfall der K-Werte erfolgt gelegentlich zuerst sehr plötzlich, in anderen Fällen von vornherein allmählich, sodaß die K-Werte im Anfang der Reaktion stets eine erhebliche Unsicherheit aufweisen. Nach einer gewissen Zeit haben sich dann aber die Parallelversuche gewöhnlich auf eine ziemlich gleiche Reaktionsgeschwindigkeit eingestellt. Es läßt sich aus diesem Grunde nicht mit Sicherheit sagen, ob das scheinbare Verschwinden des Ganges bei alternden Lösungen wirklich als ein Stabilerwerden der Fermentlösung aufzufassen ist oder ob nicht auch eine gesteigerte Hydroperoxydempfindlichkeit in den ersten Phasen der Reaktion hierfür die Ursache bildet.

Wir haben versucht, diese Frage zu entscheiden, indem wir gerade die ersten Phasen der Reaktion genau zu verfolgen uns bemühten. Dazu wurde eine Fermentlösung bestimmter Konzentration zu gleichen Teilen in mehrere Reaktionsgefäße verteilt und das Peroxyd darauf zu bestimmten Zeiten zugegeben und die Reaktion in den einzelnen Reaktionsgefäßen durch Säurezusatz nach bestimmter Zeit unterbrochen. Doch häufen sich bei einer solchen Meßmethode die Versuchsfehler so sehr, daß es schwer ist, bindende Schlüsse aus den hierbei gefundenen K-Werten über den wahren Reaktionsverlauf zu ziehen.

Unter diesen Umständen war es wertvoll, daß unter den Katalaselösungen anderer Herkunft solche zu finden sind, die 
ein in mancher Hinsicht regelmäßigeres Verhalten erkennen lassen als das Blutferment. Das sind die Extrakte, welche durch Verreiben der ganzen Körper von Raupen und Puppen von Schmetterlingen erhalten wurden. Diese Extrakte sind zunächst stark trübe und gefärbt, Eigenschaften, die sich auch durch häufige Filtration nicht ganz beseitigen lassen. Man kann jedoch aus diesen trüben Lösungen durch längeres Stehenlassen, wobei sich die suspendierten Gewebsteile absetzen, völlig klare Lösungen gewinnen. Rascher ist dies zu erreichen durch kurze Behandlung der Extrakte mit Adsorptionsmitteln wie Tierkohle, Bolus alba, Aluminiumhydroxyd. ${ }^{1}$ ) Ebenso lassen sich aus diesen Extrakten, wie dies schon früher beschrieben wurde, mit Leichtigkeit Alkoholfällungen gewinnen, die nach dem Trocknen beim Extrahieren mit Wasser stark aktive Lösungen liefern und nur noch ganz geringe Mengen von Verunreinigungen enthalten können. Alle diese Extrakte verhalten sich bezüglich ihrer kinetischen Eigenschaften bei der Peroxydzersetzung völlig gleich (vgl. Mitt. II). Sie zeigen nämlich bei $0^{\circ}$ und sehr geringer Peroxydkonzentration, wie wir dies schon in unserer letzten Mitteilung dargelegt haben, einen außerordentlich starken Abfall der K-Werte, der zunächst uns veranlaßte, hier einen charakteristischen Unterschied im Verhalten von Blut- und Raupenferment zu konstatieren.

Der Gang beim Raupenferment läßt sich aber ebensowenig und zwar aus denselben Gründen wie beim Blutferment als Oxydationswirkung auffassen, obgleich er zweifellos wieder

1) Betreffs der Wirkung von Adsorptionsmitteln sei noch folgendes erwähnt. Längeres Schütteln der Fermentlösungen mit den genannten Adsorptionsmitteln bewirkt eine fast vollständige Inaktivierung. Läßt man die Adsorptionsmittel nur kurze Zeit einwirken, so erhält man je nach der Einwirkungszeit Lösungen verschiedener Aktivität, die jedoch den völlig gleichen Reaktionsverlauf liefern. Die Wirkungsweise der verschiedenen Adsorptionsmittel untereinander verglichen ist nur quantitativ verschieden. Blutkohle wirkt am stärksten, $\mathrm{Al}(\mathrm{OH})_{\mathbf{s}}$ und Bolus alba schwächer. Dies sei mit Rücksicht auf die Versuche von L. Michaelis über die Adsorbierbarkeit anderer Fermente und mit Rücksicht auf eine event. Fraktionierung der Katalase mit Hilfe der genannten Adsorbentien hervorgehoben. 


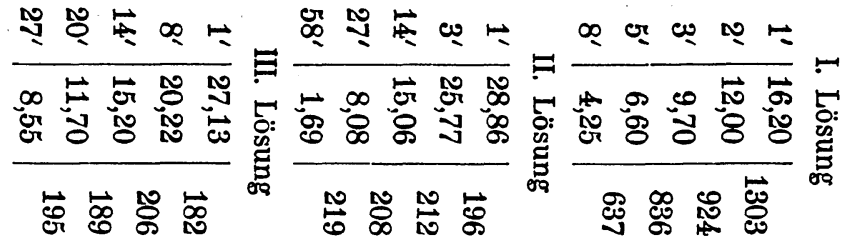

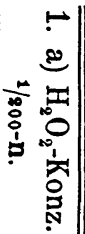

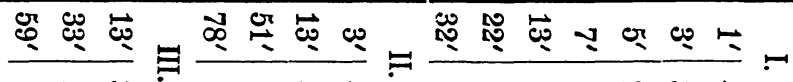

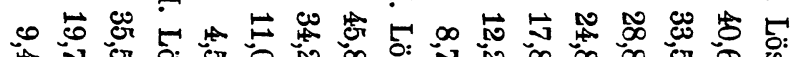
年等

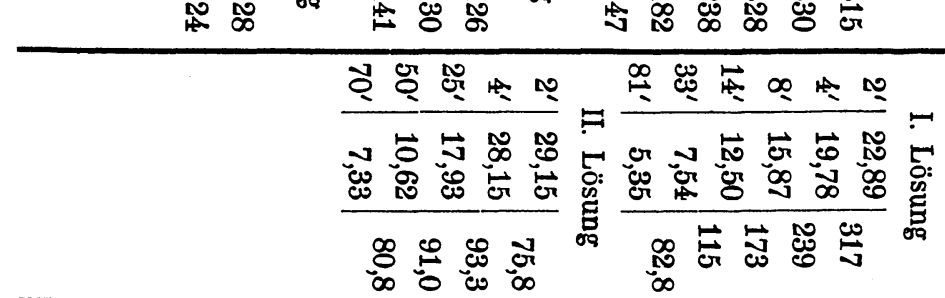

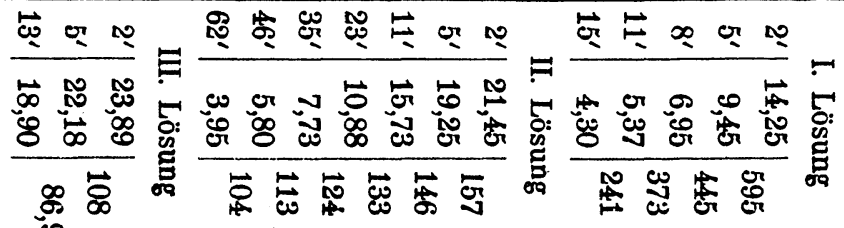

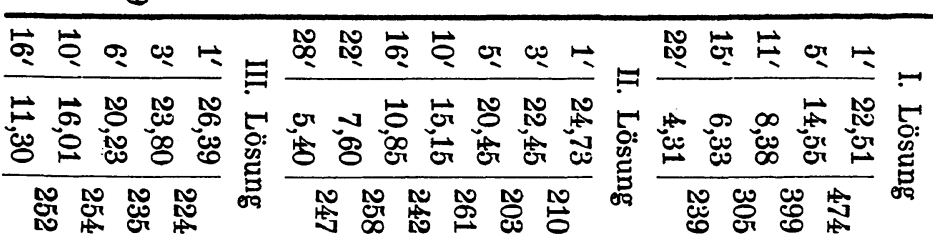

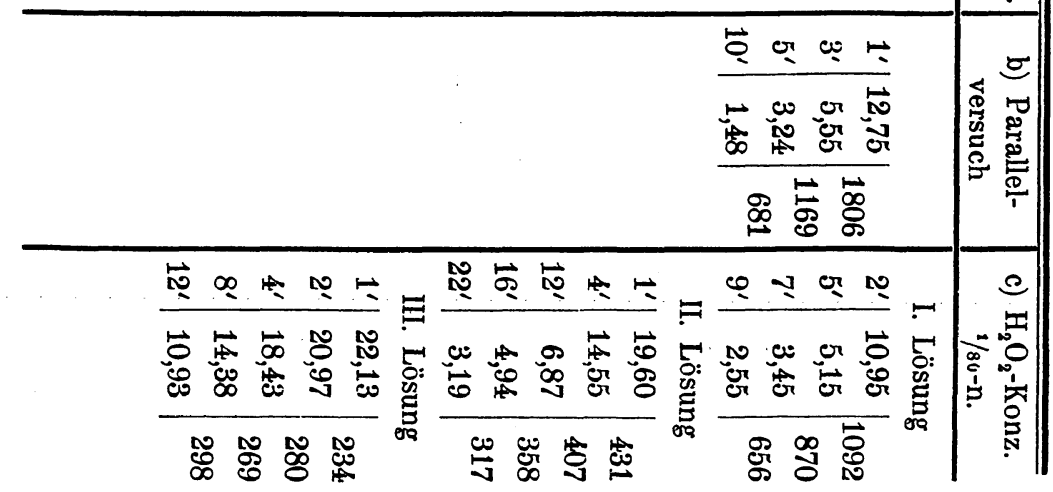


als eine Fermentschwächung durch das Peroxyd des Reaktionsgemisches $\mathrm{zu}$ betrachten ist. Dafür spricht in erster Linie der ganze Verlauf der Reaktion: Die durch den Abfall der K-Werte sich dokumentierende Aktivitätsschwächung ist auch hier durchaus unregelmäßig, sie erfolgt unter genau den gleichen Bedingungen sehr verschieden rasch, was ganz enorme Schwankungen der Anfangs-K-Werte zur Folge haben kann, führt aber, wenn die Reaktionsbedingungen im übrigen gleich sind, schließ-lich unabhängig von der Höhe der Anfangs-K-Werte zu gleicher Einstellung der Reaktionsgeschwindigkeit. Auch der Betrag des Ganges kann bei verschiedenen Fermentlösungen recht verschieden sein, und wir haben auch Raupenfermentlösungen mit sehr geringem Abfall der K-Werte in den Händen gehabt; ja es tritt auch der Fall ein, daß eine Fermentlösung durch Altern unter gleichzeitigem starken Aktivitätsverlust ihren Gang vollständig verliert (Tab. 6). Daß jedoch, wie das häufig bei Blutfermentlösungen vorkommt, eine Fermentlösung von vornherein überhaupt keinen Gang zeigt, tritt nur ganz selten auf. Die

Tabelle 6. Einfluß des Alters der Fermentlösung bei Raupenextrakten.

Sphinx ligustri. $\mathrm{H}_{2} \mathrm{O}_{8} 1 / 400-\mathrm{n} .0^{\circ}$.

\begin{tabular}{c|c|c|c|c|c}
\hline \multicolumn{3}{c|}{ 1. Frischer Extrakt } & \multicolumn{3}{c}{ 2. 3 Tage alter Extrakt } \\
\hline $1^{\prime}$ & 10,58 & 851 & \multicolumn{3}{|c}{ I. Lösung } \\
$3^{\prime}$ & 6,15 & 479 & $2^{\prime}$ & 14,24 & 354 \\
$7^{\prime}$ & 4,60 & 479 & $5^{\prime}$ & 11,15 & 285 \\
$11^{\prime}$ & 3,33 & 351 & $8^{\prime}$ & 9,16 & 277 \\
$16^{\prime}$ & 2,56 & 228 & $12^{\prime}$ & 7,10 & 262 \\
& & & $17^{\prime}$ & 5,25 & 252 \\
& & & $24^{\prime}$ & 3,50 & \\
& & & & II. Lösung \\
& & & $2^{\prime}$ & 17,95 & 255 \\
& & & $5^{\prime}$ & 15,05 & 268 \\
& & & $8^{\prime}$ & 12,51 & 255 \\
& & & $12^{\prime}$ & 9,89 & 261 \\
& & & $17^{\prime}$ & 7,32 & 248 \\
& & & $24^{\prime}$ & 4,91 & \\
& & & &
\end{tabular}


Regel ist, daß ein Extrakt aus der Körpersubstanz von Raupen und Puppen scheinbar unabhängig von ihrem Reinheitsgrade den charakteristischen starken Gang bei $0^{0}$ zeigt und ihn auch trotz langen Stehens so gut wie unverändert beibehält. Auch für den Einfluß der Peroxydkonzentration bei der Reaktionstemperatur von $0^{\circ}$ läßt sich ähnliches sagen, wie beim Blutferment, $d . h$. bis $1 / 80 \mathrm{n}$. ist kein bestimmter Einfluß feststellbar, da die Geschwindigkeit der Reaktion, wenn sie nach einiger Zeit sich dem Schema der Reaktion erster Ordnung angepaßt hat, in $1 / 80$-n-Lösungen ebenso groß ist wie in $1 / 200$ oder $1 / 400 \mathrm{n}$., auch für den Fall, daß, wie es häufig, jedoch wie Versuch Nr. 2 und 3 in Tab. 5 zeigt, keineswegs immer der Fall ist, die Anfangskonstanten niedriger bei $1 / 80 \mathrm{n}$. als bei 1/400 n. liegen. Ébenso verbietet sich die Oxydationshypothese mit Rücksicht auf die Beeinflussung der fermentativen Hydroperoxydzersetzung mit Raupenferment durch Erhöhung der Reaktionstemperatur. Bei Reaktionstemperatur von $20^{\circ}$ erhält man nämlich eine bedeutend bessere Anpassung an den Reaktionsverlauf der ersten Ordnung, was hier ebenso schwierig zu erklären wäre, wenn das Hydroperoxyd oxydierend wirkte (vgl. Mitteilung II, Tab. 8 u. 9, S. 195 in Bd. 76 dieser Zeitschrift).

$\mathrm{Da}$ somit die Sentersche Oxydationshypothese als Erklärung für den absteigenden Gang versagt, so fragt es sich, ob Senters sonstige theoretische Vorstellungen über die Kinetik der fermentativen Hydroperoxydzersetzung, von denen im Anfang die Rede war, hier Aufschluß zu geben imstande sind. Dazu bedarf es einer kurzen Diskussion derselben.

\section{Wirkung der Sauerstoffbläschen.}

Senters Auffassung über die Natur der fermentativen Hydroperoxydzersetzung ist die folgende. Er sucht das Analogon dazu bei derjenigen chemischen Reaktion im makroheterogenen System, bei der nach Nernst und Brunner ${ }^{1}$ ) die gemessene Reaktionsgeschwindigkeit auf einen Diffusionsvorgang des reagierenden Stoffes zurückgeführt werden kann, während der

1) Zeitschr. phys. Chem., Bd. 47, S. 52 (1904). 
eigentliche chemische Vorgang an der Grenzfläche der beiden Phasen mit praktisch unendlich großer, also nicht meßbarer Geschwindigkeit verläuft. Die gemessene Reaktionsgeschwindigkeit bleibt dann diejenige einer Reaktion erster Ordnung, d. $h$. sie ist der Konzentration des reagierenden Stoffes in der Lösung proportional, wenn nur durch genügende Rührung dafür gesorgt wird, daß die Konzentration in allen Teilen der Flüssigkeit gleich ist. Der Unterschied zwischen dem Fermentprozesse und dem Vorgange im makroheterogenen System besteht nur darin, daß infolge der Brownschen Molekularbewegung der Colloidteilchen des Ferments, an dessen Oberfläche die Reaktion vor sich geht, die künstliche Rührung unnötig wird.

$\mathrm{Daß}$ die gemessene Reaktionsgeschwindigkeit ein Diffusionsvorgang ist, ergibt sich nach Senter aus der Kleinheit des Temperaturkoeffizienten der Reaktion, der den Betrag 1,5 im Intervall von $0^{0}-10^{\circ}$ besitzt, während er für die als Diffusionsvorgänge erkannten Reaktionen im makroheterogenen System ungefähr 1,2 beträgt. Ferner ergibt sich dies nach Senter aus weiteren Abweichungen von den normalen chemischen Reaktionsgesetzen, welche die fermentative Hydroperoxydzersetzung in gleicher Weise wie die Platinkatalyse zeigen soll, die schon von Bredig und seinen Mitarbeitern als ein katalytischer Vorgang im mikroheterogenen System charakterisiert wurde, und auf die die Nernst-Brunnersche Hypothese, wenn auch etwas modifiziert, Anwendung finden könne. Sie bestehen erstens darin, daß bei höherer Ferment- und Peroxydkonzentration die Geschwindigkeit schneller als die Katalysatorkonzentration zunimmt, zweitens, daß in stärkeren Peroxydlösungen die Geschwindigkeitskonstanten etwas abnehmen, und drittens, daß unter gewissen Bedingungen die nach erster Ordnung berechneten K-Werte einen aufsteigenden Gang zeigen.

Die erstgenannte Abweichung wird nämlich von Senter dadurch erklärt, daß einmal die durch größere Fermentkonzentration bedingte stärkere Sauerstoffentwicklung durch Konvektion einen erhöhten Peroxydumsatz bedingt und daß zweitens die durch die Brownsche Molekularbewegung der Teilchen mit wachsender Konzentration zunehmende Durchrührung der Flüs- 
sigkeit den Diffusionsweg verkürzt und so ebenfalls die Reaktionsgeschwindigkeit steigert. Die zweite Abweichung beruhe hingegen darauf, daß der Diffusionsprozeß in den konzentrierteren Peroxydlösungen durch die an der Oberfläche der Partikelchen reichlicher entwickelten Sauerstoffbläschen in höherem Maße gestört werde. Für die an dritter Stelle genannte Abweichung wird zur Erklärung ebenfalls die Störung der Diffusion durch Sauerstoffbläschen herangezogen, die, solange die Peroxydkonzentration hoch ist, groß sei, mit deren Abnahme aber immer mehr zurücktrete, wodurch sich eine Reaktionsbeschleunigung innerhalb des Reaktionsverlaufs ergeben würde.

Hierzu ist zunächst zu sagen, daß die Sentersche Hypothese von vornherein über den Reaktionsverlauf überhaupt nichts auszusagen gestattet, da sie in beliebiger Weise zur Auslegung jedes Reaktionsverlaufs herangezogen werden könnte. Denn erörtern wir unter der Annahme, daß derartige Vorgänge, wie sie Senter annimmt, eintreten, den Einfluß dieser Erscheinung auf den Reaktionsverlauf, so ergibt sich folgendes: $\mathrm{Ob}$ die Tendenz zur Sauerstoffbläschenbildung während der Reaktion steigt oder abnimmt, läßt sich von vornherein nicht entscheiden, da der begünstigenden Wirkung durch zunehmende Sättigung der Flüssigkeit die verzögernde durch die Reaktionsverlangsamung entgegensteht. Aber gesetzt den Fall, daß diese Tendenz während des Reaktionsverlaufs stets einen bestimmten Sinn besäße, so läßt sich diese wieder sowohl für die Erklärung einer $\mathrm{Zu}$ - als einer Abnahme der Reaktionsgeschwindigkeit verwerten, je nachdem man annimmt, daß die sich entwickelnden Sauerstoffbläschen eine Durchrührung der Flüssigkeit und damit eine Verkleinerung des Diffusionsweges oder eine Verkleinerung der Colloidoberfläche begünstigen.

Da Senter bei seinen Versuchen, bei denen andere Nebenerscheinungen ausgeschlossen waren, entweder eine Konstanz der K-Werte oder eine Zunahme derselben beobachtete, so mußte er jedenfalls annehmen, daß die erste Wirkung die zweite entweder überträfe oder in den meisten Fällen gerade kompensiere, obgleich von vornherein nicht einzusehen war, weshalb nicht auch das Umgekehrte eintreten solle, was eine 
Reaktionsverzögerung zur Folge gehabt haben würde. Solange es also nicht möglich ist, zu zeigen, daß bei einem aufsteigenden Gang die Rührwirkung der Sauerstoffbläschen der die Diffusion erschwerenden Wirkung das Übergewicht hält und bei einem absteigenden Gang das Umgekehrte statthat, bleibt die Sentersche Auffassung rein hypothetisch, wodurch es wohl berechtigt erscheint, daß wir sie nicht ohne weiteres als erwiesen angenommen haben. Es sollen aber einige Punkte angeführt werden, welche gegen die Sentersche Auffassung sprechen.

Wenn man die Senterschen Versuche selbst betrachtet, bei denen er einen aufsteigenden Gang beobachtete, also die Sauerstoffbläschenbildung in Frage kam, ist es auffällig, daß sie gerade Hydroperoxydkonzentrationen entsprechen, bei denen die Gasentwickelung entweder außerordentlich gering oder überhaupt nicht zu erwarten war, also nach Senters eigenen Angaben $^{1}$ ) (vgl. Diese Zeitschr. Bd. 52, S. 743 [1903]) Abweichungen vom normalen Reaktionsverlaufe nicht eintreten durften. Ferner ließe sich wohl erwarten, daß in denjenigen Fällen seiner Versuche die Tendenz zu einem aufsteigenden Gang (vorausgesetzt, daß andere Komplikationen vermieden waren), am größten wäre, wenn das Verhältnis Hydroperoxyd zu Ferment am meisten zugunsten des ersteren verschoben war. Jedoch auch dies läßt sich aus den an der genannten Stelle angeführten Versuchen nicht folgern.

Wir haben deshalb versucht, die offene Frage, ob die durch Sauerstoffbläschen in der Flüssigkeit hervorgerufene Rührwirkung überhaupt einen- merklichen Einfluß auf den Reaktionsverlauf haben könne, so gut es geht, experimentell zu prüfen.

Wir verbanden deshalb die Reaktionskölbchen mit einer Gasbürette, die mit einem Niveaurohr versehen war, und statteten sie mit einem Rührwerk aus, sodaß also die Gasentwickelung im Reaktionsgemisch sowohl bei ruhender Flüssigkeit wie während einer sehr kräftigen Durchrührung (über die

1) Streng genommen allerdings dürfte ja die Peroxydkonzentration in der Lösung ca. 1/1000-Normalität nicht überschreiten, damit sich aller aus dem Peroxyd entwickelbarer Sauerstoff lösen könnte, doch ist natürlich stets mit starken Übersättigungserscheinungen zu rechnen (siehe später). 
Einzelheiten der Versuchsordnung wird an anderer Stelle ausführlich berichtet werden) verfolgt werden konnte. Es wurden Versuche sowohl bei $0^{\circ}$ als bei $20^{\circ}$ und mit wechselnder Hydroperoxyd- und Fermentkonzentration vorgenommen. Die Versuche sind im folgenden mitgeteilt. (Tab. 7.) Es erhellt, daß bei ruhender Flüssigkeit, wie schon der Augenschein wahrscheinlich gemacht hatte, und bei nicht zu großer Hydroperoxydund Fermentkonzentration bei $0^{\circ}$ wenigstens fast während des ganzen Verlaufs der Reaktion eine Gasabgabe überhaupt nicht stattfindet, Verhältnisse, die sich bei $20^{\circ}$ wiederholen, nur

Tabelle 7a. Sauerstoffentwicklung während der Reaktion bei ruhender Flüssigkeit.

\begin{tabular}{|c|c|c|c|c|c|c|c|}
\hline \multirow{2}{*}{\multicolumn{2}{|c|}{$\begin{array}{c}\text { a) Fermentkonz. } 1,5 \\
\mathrm{H}_{2} \mathrm{O}_{2} \text {-Konz. } 1 / 100-\mathrm{n} \\
\doteqdot 20,9 \mathrm{ccm} \mathrm{O}_{2} \\
\text { bei } 0^{\circ} \text { und } 760 \mathrm{~mm} \mathrm{Hg}\end{array}$}} & \multicolumn{3}{|c|}{$\begin{array}{l}\text { b) Fermentkonz. } 5 \\
\mathrm{H}_{2} \mathrm{O}_{2} \text {-Konz. } 1 / 100-\mathrm{n} \\
\doteqdot 20,9 \mathrm{ccm} \mathrm{O} \mathrm{O}_{2}\end{array}$} & \multicolumn{3}{|c|}{$\begin{array}{l}\text { c) Fermentkonz. 1,5 } \\
\mathrm{H}_{2} \mathrm{O}_{2}-\mathrm{Konz} .1 / 20-\mathrm{n} \\
\doteqdot 104,5 \mathrm{ccm} \mathrm{O}_{2}\end{array}$} \\
\hline & & $\begin{array}{c}\text { Zeit } \\
\text { in } \\
\text { Min. }\end{array}$ & \begin{tabular}{|c|} 
Ent- \\
wickelter \\
$\mathrm{O}_{2}$ in ccm \\
\end{tabular} & \begin{tabular}{|l}
$\ln \mathrm{je}$ \\
$5 \mathrm{Min}$. \\
entw. $\mathrm{O}_{2}$
\end{tabular} & $\begin{array}{c}\text { Zeit } \\
\text { in } \\
\text { Min. }\end{array}$ & $\begin{array}{c}\text { Ent- } \\
\text { wickelter } \\
\mathrm{O}_{2} \text { in ccm }\end{array}$ & \begin{tabular}{|} 
In je \\
$5 \mathrm{Min}$. \\
entw. $\mathrm{O}_{2}$
\end{tabular} \\
\hline \multirow{8}{*}{$0^{\circ}$} & in 23 Minuten keine & $2^{\prime}$ & 0,5 & & $6^{\prime}$ & 1,0 & \\
\hline & Gasentwicklung ${ }^{1}$ ) & $12^{\prime}$ & 1,3 & & $21^{\prime}$ & 3,9 & \\
\hline & & $17^{\prime}$ & 1,8 & & $36^{\prime}$ & 7,3 & 1,1 \\
\hline & & $22^{\prime}$ & 2,3 & U,0 & $56^{\prime}$ & 12,4 & 1,0 \\
\hline & & $33^{\prime}$ & 3,2 & & $71^{\prime}$ & 15,9 & \\
\hline & & $43^{\prime}$ & 4,1 & & & & \\
\hline & • & $50^{\prime}$ & 4,6 & & & & \\
\hline & $\begin{array}{l}\text { a) Fermentkonz. } 1,5 \\
\mathrm{H}_{2} \mathrm{O}_{2} \text {-Konz. } 1 / 200-\mathrm{n} \\
\doteqdot 10,5 \mathrm{ccm} \mathrm{O}_{2}\end{array}$ & \multicolumn{3}{|c|}{ 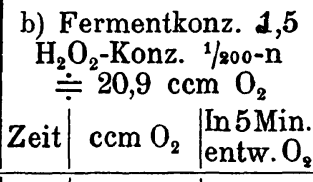 } & \multicolumn{3}{|c|}{ 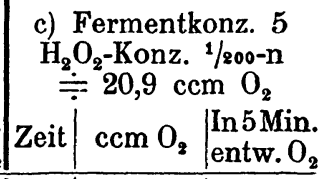 } \\
\hline \multirow{7}{*}{$17^{\circ}$} & in 26 Minuten nur & $1^{\prime}$ & 0,4 & & $6^{\prime}$ & 1,3 & \\
\hline & $0,6 \mathrm{ccm} \mathrm{O}_{2}$ entwickelt & $6^{\prime}$ & 0,75 & 0,45 & $11^{\prime}$ & 2,0 & 0,6 \\
\hline & & $11^{\prime}$ & 1,2 & 0,4 & $16^{\prime}$ & 2,6 & \\
\hline & Nach Schluß des Ver- & $16^{\prime}$ & 1,6 & $\begin{array}{l}0,4 \\
0,4\end{array}$ & $21^{\prime}$ & 3,3 & 0,4 \\
\hline & s wurde stets durch & $21^{\prime}$ & 2,0 & & $26^{\prime}$ & 3,7 & 0.35 \\
\hline & ellit, daß alles $\mathrm{H}_{2} \mathrm{O}_{2}$ zer- & $26^{\prime}$ & 2,4 & & $31^{\prime}$ & 4,05 & 035 \\
\hline & & $31^{\prime}$ & 2,8 & & $36^{\prime}$ & 4,4 & \\
\hline
\end{tabular}


Über die fermentative Hydroperoxydzersetzung. III.

Tabelle $7 \mathrm{~b}$. Versuch zur Bestimmung der Aufnahmefähigkeit der Fermentlösung für den während der Reaktion entwickelten Sauerstoff.

$\mathrm{H}_{2} \mathrm{O}_{2}$-Konz. 1/100-n. $0^{0}$.

\begin{tabular}{|c|c|c|c|}
\hline & $\begin{array}{c}\text { Zeit } \\
\text { in Min. }\end{array}$ & $\begin{array}{c}\text { Entwickelter } \mathrm{O}_{2} \\
\text { in } \mathrm{ccm}\end{array}$ & $\begin{array}{c}\text { In je } 10^{\prime} \\
\text { entwickelter } O_{2}\end{array}$ \\
\hline I. & $\begin{array}{r}0^{\prime} \\
60^{\prime} \\
67^{\prime}\end{array}$ & $\begin{array}{l}0 \\
0,6 \\
0,9\end{array}$ & - \\
\hline II. & $\begin{array}{r}80^{\prime} \\
85^{\prime} \\
95^{\prime} \\
105^{\prime} \\
115^{\prime} \\
125^{\prime} \\
135^{\prime} \\
145^{\prime}\end{array}$ & $\begin{array}{l}1,7 \\
1,8 \\
2,2 \\
2,8 \\
3,4 \\
4,3 \\
5,1 \\
5,6\end{array}$ & $\begin{array}{l}- \\
0,4 \\
0,6 \\
0,6 \\
0,9 \\
0,8 \\
0,5\end{array}$ \\
\hline III. & $\begin{array}{l}150^{\prime} \\
160^{\prime} \\
170^{\prime} \\
230^{\prime} \\
240^{\prime} \\
250^{\prime} \\
260^{\prime} \\
275^{\prime} \\
290^{\prime}\end{array}$ & $\begin{array}{r}5,9 \\
6,9 \\
7,9 \\
9,3 \\
10,5 \\
11,1 \\
12,3 \\
13,2 \\
14,1\end{array}$ & $\begin{array}{c}1,0 \\
1,0 \\
1,4 \text { in } 60^{\prime} \\
1,2 \\
0,6 \\
1,2 \\
0,6 \\
0,6\end{array}$ \\
\hline IV. & $\begin{array}{l}295^{\prime} \\
305^{\prime} \\
315^{\prime} \\
325^{\prime} \\
335^{\prime} \\
350^{\prime} \\
360^{\prime} \\
370^{\prime} \\
380^{\prime} \\
390^{\prime} \\
400^{\prime} \\
410^{\prime}\end{array}$ & $\begin{array}{l}14,8 \\
15,7 \\
16,5 \\
17,4 \\
18,4 \\
19,3 \\
20,3 \\
21,1 \\
22,4 \\
23,2 \\
23,9 \\
24,5\end{array}$ & $\begin{array}{l}0,9 \\
0,8 \\
0,9 \\
1,0 \\
0,6 \\
1,0 \\
0,8 \\
1,3 \\
0,8 \\
0,7 \\
0,6\end{array}$ \\
\hline
\end{tabular}


mit dem Unterschied, daß die Hydroperoxyd- und Fermentkonzentrationsgrenze, bei der eine merkliche Gasentwickelung einsetzt, etwas nach unten verschoben ist. Es folgt daraus, daß bei weitem die größte Menge des Gases in der Flüssigkeit gelöst enthalten bleibt, ${ }^{1}$ ) unter diesen Umständen also eine Rührwirkung durch Sauerstoffbläschen überhaupt nicht eintreten kann. Aber auch in den Fällen, in denen eine merkliche Sauerstoffentwickelung zu beobachten ist, kann sie nicht störend auf den Reaktionsverlauf einwirken, denn wie alle Versuche dieser Art ergaben, ist die allerdings stets geringe Gasentwickelung während der ganzen Versuchsdauer ziemlich gleichförmig, d. h. es werden in gleicher Zeit ziemlich die gleichen Mengen Gas abgegeben (vgl. Tab. $7 \mathrm{a}$ u. 7 b). ${ }^{2}$ ) Es wird also mithin auch die Zahl der die Flüssigkeit in der Zeiteinheit durchsetzenden Gasbläschen und die Rührwirkung während der Versuchsdauer konstant sein! Damit ist aber erwiesen, daß die Rührwirkung der 0-Bläschen den Gang nicht verursachen kann. Es erübrigt sich dann auch die Frage, ob der von Senters in Rücksicht gezogene entgegengesetzte Effekt der Bläschenbildung (Beeinträchtigung der Diffusionsoberfläche durch letztere) den regelmäßigen Ablauf der Reaktion stören kann: Denn wenn entweder überhaupt keine merkliche Gasentwicklung beobachtet wird oder diese gleichförmig ist, so kann, wenn man annimmt, daß ein Teil des sich in letzterem Fall entwickelnden Gases in Form an den Kolloidteilchen adhäsierender Gasbläschen auftritt, die daraus resultierende Wirkung auf den Reaktionsverlauf nur als eine Reaktionsverzögerung gedacht werden.

1) Versuchsanordnungen wie die von W. Löb (Bioch. Zeitschrift, Bd. 13, S. 339, 1902) beschriebene zur Messung der Katalase im Blut können daher kaum richtige Aufschlüsse über, die in Wirklichkeit zersetzten Sauerstoffmengen liefern.

2) In Tabelle $7 \mathrm{~b}$ ist ein Versuch mitgeteilt; bei dem die Reaktion durch wiederholten $\mathrm{H}_{2} \mathrm{O}_{2}$-Zusatz über eine längere Zeit ausgedehnt wurde. Man sieht, daß auch hier die Gasmengen, die entwickelt werden, relativ sehr gering und ziemlich konstant sind für gleiche Zeitintervalle. Die in der Lösung verbleibenden Sauerstoffmengen sind sehr erheblich: in $208 \mathrm{ccm}$ verbleiben $35,8 \mathrm{~cm} 0_{2}$, die einem Gleichgewichtsdruck von über $15 \mathrm{Atm}$. entsprechen würden. 
$\mathrm{Da} \beta$ der fehlende Sauerstoff in Form einer übersättigten Lösung in dem Reaktionsgemisch enthalten ist, läßt sich leicht zeigen: Wenn man am Ende der Zeit, welche die Reaktion zu ihrem Ablauf nötig hat, das Rührwerk in Gang setzt, wird in kurzer Zeit ein großer Teil des Gases aus der Flüssigkeit entwickelt.

Es fragt sich nun, ob die hierbei eintretende außerordentlich lebhafte Bläschenbildung wenigstens einen Einfluß auf den Reaktionsverlauf haben könnte. Um dies festzustellen, verfuhren wir so, daß wir den Reaktionsverlauf einmal in ruhender, das andere Mal in einer stark geschüttelten Reaktionsflüssigkeit verfolgten oder indem wir das gleiche Reaktionsgemisch zunächst bei ruhender, nach einiger Zeit bei geschüttelter Flüssigkeit untersuchten. Das Ergebnis einer sehr großen Anzahl Versuche in dieser Richtung war nicht eindeutig. In einigen Fällen wurde eine merkliche Zunahme der Reaktionsgeschwindigkeit durch das Schütteln festgestellt, in anderen wieder fehlte sie vollkommen. Ließ man anderseits die stark in Bewegung befindliche Flüssigkeit zur Ruhe kommen, so konnte häufig ein merklicher Rückgang der Reaktionsgeschwindigkeit festgestellt werden. (Tab. 8 u. 9.)

Tabelle 8. Einfluß des Schüttelns bei Atmosphärendruck.

Blutferment. $\mathrm{H}_{\mathbf{z}} \mathrm{O}_{\mathbf{z}}$-Konz. ${ }^{1 / 100-\mathrm{n} .} \mathrm{0}^{0}$.

Die Versuche wurden in der angegebenen Reihenfolge unmittelbar hintereinander ausgeführt.

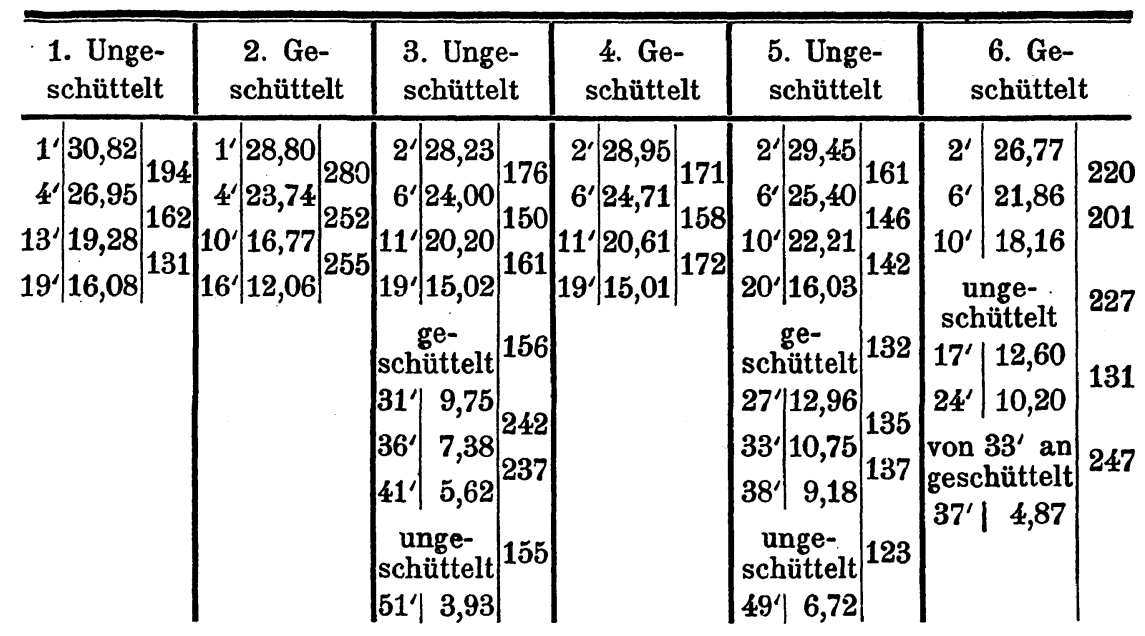


Tabelle 9. Einfluß des Schüttelns bei Atmosphärendruck. Puppenextrakt von Deilephila euphorbiae. $\mathrm{H}_{2} \mathrm{O}_{\mathbf{z}}$-Konz. 1/400-n. $20^{\circ}$.

\begin{tabular}{|c|c|c|}
\hline anges & hüttelt & \\
\hline $1^{\prime}$ & 18,30 & \\
\hline $3^{\prime}$ & 13,05 & \\
\hline $6^{\prime}$ & 8,61 & \\
\hline ges & ü̈ttelt & \\
\hline $9^{\prime}$ & $\check{5}, 70$ & \\
\hline $12^{\prime}$ & 3,40 & \\
\hline unges & hüttelt & \\
\hline $22^{\prime}$ & 1,06 & \\
\hline
\end{tabular}

Tabelle 10. Einfluß des vorherigen Schüttelns der Fermentlösung.

Blutferment. $\mathrm{H}_{2} \mathrm{O}_{2}$-Konz. $1 / 800-$ n. $20^{\circ}$.

\begin{tabular}{r|r|r|r|r|l}
\hline \multicolumn{3}{c|}{ 1. ungeschüttelt } & \multicolumn{3}{|c}{ 2. 30 Min. auf Schüttelmaschine geschüttelt } \\
\hline $1^{\prime}$ & 20,03 & 740 & $1^{\prime}$ & 16,75 & 738 \\
$5^{\prime}$ & 10,13 & 796 & $4^{\prime}$ & 10,06 & 767 \\
$10^{\prime}$ & 4,05 & & $12^{\prime}$ & 2,45 &
\end{tabular}

Um die Beweiskraft dieser Versuche zu erhöhen, mußte noch ein Bedenken beseitigt werden. Es betrifft die Wirkung des Schüttelns auf das Ferment. Nach Versuchen anderer Autoren ${ }^{1)}$ können Fermente durch bloßes Schütteln in ihrer Aktivität stärk geschwächt werden. Entsprechende Versuche mit dem Ferment in der Reaktionsverdünnung ${ }^{2}$ ) lieferten keine positiven Ergebnisse, sodaß von einer Wirkung in dieser Richtung abgesehen werden kann (Tab. 10). Wenn also damit bewiesen schien, daß das Schütteln keine Aktivitätsänderung des Ferments an sich in der Reaktionsverdünnung hervorrief, so mußte nach obigem eine, wenn auch nicht regelmäßig, so doch häufig eintretende Wirkung des Schüttelns auf den Reaktionsverlauf

1) E. Abderhalden und M. Guggenheim (für Tyrosinase, Hefepreßsaft und Pankreassaft), Diese Zeitschrift, Bd. 54 (1908) u. a.

2) Konzentrierte Katalaselösungen zeigen dagegen allerdings bei mehrstündigem Schütteln auf der Schüttelmaschine im geschlossenen Gefäß bei Zimmertemperatur einen erheblichen Rückgang ihrer Aktivität. 
selbst angenommen werden und es läge nichts im Wege, diese im Sinne Senters durch eine Rührwirkung der Sauerstoff bläschen zu erklären. Eine Erklärung aber von Abweichungen des Reaktionsverlaufs vom Reaktionsschema I. Ordnung in der ruhenden Flüssigkeit konnte der erhaltene Befund nicht geben.

\section{Einfluß der Adsorption.}

Die ganze Sachlage ändert sich aber sofort, wenn man nicht die Rührwirkung des sich entwickelnden Sauerstoffs, sondern den in der Flüssigkeit gelösten Sauerstoff für die störende Wirkung verantwortlich macht. Aus der Tatsache nämlich, daß durch den während der Reaktion sich bildenden Sauerstoff so außerordentlich hohe Übersättigungsgrade in der Flüssigkeit sich erzielen lassen, die auch durch starke Rührwirkung nicht oder wenigstens nur sehr schwer aufzuheben sind (vgl. die früher beschriebenen Versuche), geht mit großer Wahrscheinlichkeit hervor, daß die Colloidteilchen adsorbierend auf den in Lösung befindlichen Sauerstoff wirken und so die starke Übersättigung der Lösungen ermöglichen.

Nimmt man jedoch eine merkliche Adsorption des gelösten Sauerstoffes durch die Fermentteilchen an, so liegt es auch nahe, eine solche für das Peroxyd zu berücksichtigen, d. h. also die fermentative Hydroperoxydzersetzung als ein Beispiel einer Adsorptionskatalyse aufzufassen. Fälle solcher Adsorptionskatalysen sind schon bei Gasreaktionen mehrfach untersucht und diskutiert worden (vgl. vor allen Dingen die Untersuchung von Bodenstein und seinen Mitarbeitern, ferner von Bodenstein und Stock, Ber. d. d. chem. Gesellsch., Bd. 40, S. 70 [1907]; Zeitschr. f. physikal. Chem., Bd. 60, S. 46 [1907]). Auch für Reaktionen in Flüssigkeiten ist die Adsorption besonders von Freundlich zur Erklärung des Verhaltens der Platinkatalyse des Hydroperoxyds herangezogen worden. ${ }^{1}$ )

1). Die Ansicht, daß speziell bei Fermentreaktionen möglicherweise Adsorptionsvorgänge eine wesentliche Rolle spielen könnten, ist kürzlich auch von H. G. Denham (Zeitschrift f. physik. Chem., Bd. 72 [1910], S. 684 ff.) erörtert worden. Doch weichen unsere im folgenden dargelegten Anschauungen wesentlich von den Vorstellungen Denhams ab, die wir uns, so-

Hoppe-Seyler's Zeitschrift f. physiol. Chemie. LXXIX. 
Bleiben wir also bei der Vorstellung, daß die gemessene Reaktionsgeschwindigkeit einen Diffusionsvorgang darstellt, bei dem jedoch der Diffusionsweg durch die Adsorption des gelösten Peroxyds modifiziert wird, so tritt an Stelle der für die NernstBrunnersche im makroheterogenen Systeme geltenden Gleichung

$$
-\frac{\mathrm{dx}}{\mathrm{dt}}=\mathrm{K}^{\prime} \cdot \mathrm{c},
$$

die durch die Berücksichtigung der Adsorptionsisotherme modifizierte Form

$$
-\frac{\mathrm{dx}}{\mathrm{dt}}=\mathrm{K}^{\prime} \cdot \alpha \cdot \mathrm{c}^{\frac{1}{\mathrm{n}}}
$$

worin $\alpha$ einen für das System charakteristischen Adsorptionskoeffizienten, $\frac{1}{\mathbf{n}}$ den Adsorptionsexponenten darstellt, der im allgemeinen einen echten Bruch bildet. - Die Folge dieser Annahme ist, daß die Reaktion nicht mehr nach dem Schema erster Ordnung verlaufen kann, sondern die K-Werte normalerweise mit dem Verlauf der Reaktion zunehmen müssen, weil ja nach der. Form der Adsorptionsisotherme die Adsorption in verdünnten Lösungen eine relativ stärkere sein wird, $d . h$. die Konzentration in der Nähe der Grenzfläche nicht so stark sinkt wie in der Lösung selbst, so daß die Geschwindigkeit der Diffusion eine größere wäre, als aus der Konzentration in der Lösung zu schließen ist. Nehmen wir nun aber weiter an, daß sich diese Adsorption nicht nur auf den reagierenden Stoff, sondern auch auf das Reaktionsprodukt erstreckt, so braucht man nur zu folgern, daß die sich im Verlaufe der Reaktion immer steigernde Sauerstoffadsorption durch das Ferment mit einer Schwächung des Ferments verknüpft ist, um zu verstehen, daß die nach obigen Annahmen zu erwartende Zunahme der nach einer Reaktion erster Ordnung berechneten K-Werte sich in eine scheinbare Konstanz oder Abnahme derselben verwandelt.

weit die fermentative Hydroperoxydzersetzung anlangt, nicht zu eigen machen können. 
Welcher Art diese inaktivierende Wirkung des adsorbierten Sauerstoffes ist, darüber läßt sich von vornherein nichts sagen. Wenn man jedoch an die sogenannten Giftwirkungen zahlreicher löslicher Substanzen schon in geringen Konzentrationen denkt, welche gerade bei der Katalase ${ }^{1}$ ) eine so große Rolle spielen und ihre einfachste Erklärung in den meisten Fällen in Adsorptionsvorgängen und einer damit verknüpften Ausbildung einer schwerdiffusiblen Schicht finden, so ist es sehr naheliegend; auch von gelösten Gasen, insbesondere auch von dem Sauerstoff als Reaktionsprodukt der Hydroperoxydzersetzung eine solche Wirkung anzunehmen, zumal die Möglichkeit für eine Adsorption des Sauerstoffs gerade in statu nascendi besonders günstig ist. Es ist auch wohl möglich, die während der Reaktion erfolgende Schwächung des Ferments als eine Verdrängungswirkung aufzufassen. Nach dem, was über die gleichzeitige Adsorption mehrerer Stoffe in einer Lösung bekannt ist, erscheint dies durchaus berechtigt. Nach Freundlich ${ }^{2}$ ) verdrängen sich tatsächlich adsorbierte Stoffe im allgemeinen rasch und glatt, wie in dem Beispiele Kohlenstoff, Bernsteinsäure, Benzoesäure gezeigt wurde. Und besonders wichtig scheint es für unseren Fall, was der Verfasser über die Verhältnisse bemerkt, die eintreten, wenn eine erhebliche Konzentrationsverschiedenheit zwischen den beiden Stoffen besteht, Verhältnisse, die ja in unserem Falle durch den Ablauf der Reaktion von selbst hervorgerufen werden: «Ist die Konzentration der beiden Stoffe sehr verschieden, so wird der mit der großen Konzentration, selbst wenn er allein weniger adsorbiert wird, an der Grenzfläche stark überwiegen und demgemäß, wenn man ihn als zweiten Stoff zusetzt, den ersten von der Grenzfläche verdrängen.»

Unsere Auffassung über die fermentative Hydroperoxydzersetzung stimmt also insofern mit derjenigen. Senters überein; als auch wir in dem durch Messung verfolgbaren Vorgang eine Diffusion sehen, wie sie nach Nernst und Brunner den Ablauf einer Anzahl Reaktionen im makroheterogenen System

1) Vgl. vor allen G. Senter, Zeitschr. f. physik. Chemie, Bd. 51, S. 675 (1905) und H. Freundlich, Kapillarchemie, S. $386 \mathrm{ff}$.

2) Vgl. Kapillarchemie, S. $163 \mathrm{ff}$. 
regelt, während der eigentliche chemische Zerfall des Peroxyds an der Oberfläche der Colloidteilchen mit nicht meßbarer Geschwindigkeit erfolgt. Wir weichen aber darin von Senter $\mathrm{ab}, \mathrm{da} ß$ wir der bei mikroheterogenen Systemen stets in Betracht kommenden Adsorption einen entscheidenden Einfluß auf den Diffusionsvorgang zuweisen, und zwar in doppeltem Sinne: erstens mit Rücksicht auf den reagierenden Stoff, womit wir die Ansichten Freundlichs über die Ursachen des aufsteigenden Ganges bei der Platinkatalyse ${ }^{1}$ ) auf die Katalase übertragen (vergleiche hierüber die ausführlichen Betrachtungen des genannten Autors in seinem Lehrbuch über Kapillarchemie, Seite $350 \mathrm{ff}$. und Seite 521), zweitens mit Rücksicht auf das Reaktionsprodukt, womit wir einen neuen, die Kinetik der fermentativen Hydroperoxydzersetzung bestimmenden Faktor einführen. ${ }^{2}$ )

Wenden wir nun die Erkenntnis, daß bei der fermentativen Hydroperoxydzersetzung Adsorptionsvorgänge der geschilderten Art entscheidend in den Mechanismus der Reaktion eingreifen, auf die beschriebenen Fermentversuche an, so ist nach obigem zunächst der bisher unerklärbare, so häufig beobachtete absteigende Gang ohne weiteres verständlich. Eine geringe Überlegung lehrt auch, daß bei höherer Peroxydkonzentration der Ablauf der Reaktion insgesamt langsamer erfolgen, die Konstanz der K-Werte aber eine gerade häufig bessere sein wird. Ebenso scheint die für die Reaktion so außerordentlich charakteristische schwere Reproduzierbarkeit der Versuche eine sehr gute Erklärung zu finden. Denn da der Reaktionsverlauf

1) Vgl. hierzu auch vor allen die Untersuchungen Bredigs und seiner Schüler (Diese Zeitschrift, Bd. 31, S. 258 [1899]; Bredig und Jkeda, Diese Zeitschrift, Bd. 37, S. 1 [1901]; Bredig und Reinders, Diese Zeitschrift, Bd. 37, S. 323 [1901]; Bredig und Fortner, Berl. Ber., Bd. 37, S. 798 [1904]).

${ }^{2}$ ) Diese Auffassung bildet in gewissem Sinn einen Spezialfall der von B. Moore (vgl. Bayliss, Das Wesen der Enzymwirkung, Dresden 1910) aufgestellten allgemeinen Formel für die Kinetik, einer Fermentreaktion, welche der Intensitätsänderung Rechnung trägt, die das Ferment mit fortschreitendem Umsatz erleidet: $\frac{d x}{d t}=k\left(1 \pm \mathrm{e} \frac{x}{a}\right) \cdot(a-x)$. 
nach obigem von dem Adsorptionsvermögen des Ferments mitbestimmt wird und letzteres wieder durch zahlreiche, durchaus nicht kontrollierbare Faktoren beeinflußt werden kann, so erklären sich die Schwankungen nicht nur in Hinsicht auf die Reaktionsgeschwindigkeit, sondern auch mit Hinsicht auf den Reaktionsverlauf ganz von selbst. Diese Veränderlichkeit im Reaktionsverlaufe ergibt sich jedoch nicht nur durch das jeweilig veränderliche Adsorptionsvermögen des Ferments, sondern auch durch die Tatsache, daß die Adsorption des inaktivierenden Sauerstoffs von dem Übersättigungsgrade desselben in der Lösung abhängen wird, der natürlich bei ruhender Flüssigkeit von unkontrollierbaren Faktoren bestimmt wird. Die Beobachtung insbesondere, daß Fermentschwächung durch Altern gleichzeitig eine Abnahme des absteigenden Ganges der $\mathrm{K}$-Werte bei der Reaktion zur Folge hat, ebenso wie die abnorme Empfindlichkeit der besonders gereinigten Fermentlösungen, werden durchaus verständlich. Wir haben nach ihrer Darstellung in den Fermentlösungen stets mit Verunreinigungen unbestimmter Natur und Menge zu rechnen, die selbst adsorbiert werden und dadurch Aktivität und Reaktionsverlauf modifizieren können. Ebenso erklärlich ist die Tatsache, daß bei längerem Verfolg der Reaktion das Ferment im allgemeinen sich schließlich nur noch wenig oder eventuell gar nicht mehr, auch bei wechselndem Peroxydgehalt des Reaktionsgemisches, ändert. Allmählich wird sich ein durch den erreichbaren Übersättigungsgrad der Lösung geregeltes Adsorptionsgleichgewicht einstellen. Bleibt man bei der Annahme einer Adsorptionsverdrängung, so geht aus der Tatsache, daß im allgemeinen das Ferment in verfolgbarer Zeit nicht auf die Aktivität 0 heruntergeht, hervor, daß die Adsorptionsverdrängung nie eine vollständige werden kann. Endlich läßt sich die Tatsache, daß die K-Werte bei hoher Temperatur eine bessere Konstanz aufweisen, mit der Auffassung in Einklang bringen, daß es Adsorptionsvorgänge sind, die den Gang verursachen. Wir wissen, daß die Adsorption gelöster Stoffe im allgemeinen mit wachsender Temperatur abnimmt. Hier, wo es sich um die Adsorption eines gelösten Gases handelt, wird diese Tatsache um so mehr hervor- 
treten, als auch die Löslichkeit des Gases mit steigender Temperatur kleiner wird. Bei Fermenten mit geringem Adsorptionsvermögen (kleiner Gang) wird also bei hoher Reaktionstemperatur der für die Adsorptionsreaktion charakteristische aufsteigende Gang hervortreten (vgl. Versuch 1 u. 2 in Tab. II).

Es erklären sich also die Eigenschaften des Blutferments ziemlich ungezwungen durch Berücksichtigung der Adsorptionseigenschaften desselben und man wird diese Annahme deshalb auch für die anderen Katalasen, insbesondere für die aus Raupen und Puppen isolierte, machen können, soweit sich diese in ihrem Verhalten dem Blutferment anschließen. Aus dem besonders großen Gange wird man hier auf ein besonders starkes Adsorptionsvermögen $\mathrm{zu}$ schließen haben, das wiederum mit der überhaupt auffallend starken Aktivität dieses Ferments in Beziehung zu stehen scheint.

\section{Weitere Versuche zur Stütze der Adsorptions- theorie.}

Wenn nun auch durch die bisher geschilderten Beispiele die Wahrscheinlichkeit groß geworden ist, daß wirklich Adsorptionsvorgänge der geschilderten Art entscheidend für den Verlauf der fermentativen Hydroperoxydzersetzung sind, so fehlt doch einstweilen noch ein direkter Beweis gänzlich dafür. Denn die geschilderten Schüttelversuche zeigen keine genügend beträchtliche regelmäßige. Wirkung, um als Beweis für die Richtigkeit unserer Auffassung herangezogen werden zu können. Zweitens aber lassen sie sich ebensogut für das Vorhandensein einer Wirkung im Sinne Senters verwerten: Abschüttelung von Gasbläschen von den Fermentteilchen und Unterstützung der Rührwirkung der Brownschen Molekularbewegung durch die sich in der geschüttelten Flüssigkeit leicht entwickelnden Gasbläschen, beides Vorgänge, welche die Diffusion, also denjenigen Vorgang begünstigen, der für die Geschwindigkeit der Reaktion allein maßgebend ist.

Die unregelmäßige und unvollständige Wirkung des Schüttelns konnte nur darin zu suchen sein, daß der Sauerstoff nur unvollständig aus dem Reaktionsgemisch entfernt wurde, und 
in der Tat zeigen gasvolumetrische Messungen, daß es mit Hilfe einfacher Durchrührung, auch wenn sie sehr intensiv ist, nur schwer gelingt, den in der Flüssigkeit enthaltenen Sauerstoff, wenn er einmal adsorbiert worden ist, wieder vollständig zu entfernen.

Wäre es möglich, den Sauerstoff im Entstehungszustande möglichst vollständig aus dem Reaktionsgemisch zu entfernen und gelänge es damit gleichzeitig, den absteigenden Gang der $\mathrm{K}$-Werte $\mathrm{zu}$ beseitigen, bezw. ihn in einen aufsteigenden zu verwandeln und gleichzeitig die Gesamtreaktionsgeschwindigkeit zu erhöhen, und wäre endlich eine solche Wirkung ihrem Betrage nach größer als das bloße Durchschütteln des Reaktionsgemischs während der Reaktion, so hätte damit die Adsorptionstheorie ebensoviel an Wahrscheinlichkeit gewonnen, als die Sentersche Auffassung daran verlöre.

Im folgenden sollen nun Versuche, welche in dieser Richtung angestellt wurden, besprochen werden. Die Entfernung des Sauerstoffs gelingt in viel weitgehenderem Maße als durch bloßes Schütteln an der Luft, wenn man das Schütteln im Vakuum ausführl. Zu diesem Zwecke wurde das Reaktionsgemisch in eine große Saugflasche, die mit einer gut wirkenden Wasserstrahlpumpe verbunden war, gebracht und während der Reaktion verschlossen geschüttelt. Zur Entnahme nur mußte Atmosphärendruck über dem Reaktionsgemisch hergestellt werden. Die dadurch erzielte Änderung im Reaktionsverlauf, verglichen mit dem bei Atmosphärendruck (vgl. Tab. 9) in Ruhe befindlichen Reaktionsgemisch, ist augenscheinlich und liegt in der nach der Absorptionstheorie zu erwartenden Richtung bei Versuchstemperatur von 0 bis $20^{\circ}$ : Durch Schütteln im Vakuum wird nicht nur die Reaktionsgeschwindigkeit bedeutend heraufgesetzt, sondern auch der Gang, wie oben erwähnt, aus einem absteigenden in einen aufsteigenden verwandelt (vgl. Tab. 11). Es treten also, anders ausgedrückt, dieselben Wirkungen wie beim einfachen Schütteln, nur viel prompter und deutlicher hervor. Man kann, um die Größe der Wirkung zu erkennen, statt eines Parallelversuchs mit ruhender Flüssigkeit auch die Anordnung in der Weise treffen, 
Tabelle 11a. Wirkung des Schüttelns im Vakuum. Blutferment, $\mathrm{H}_{2} \mathrm{O}_{2}$-Konz. 1/400-n.

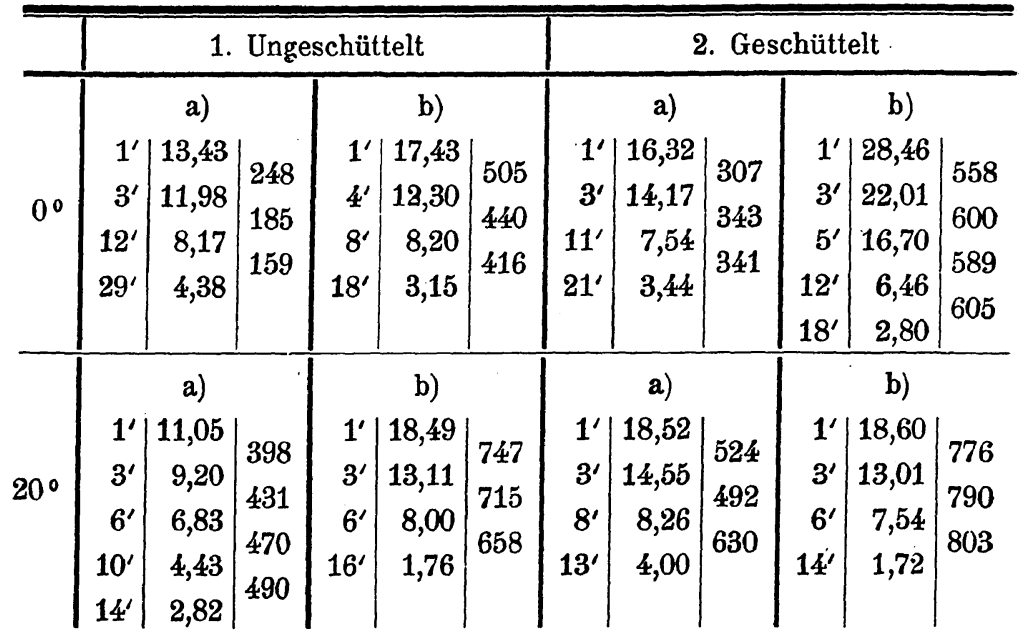

Tabelle $11 \mathrm{~b}$. Wirkung des Schüttelns im Vakuum.

Puppenextrakt von Smerinthus Ocellata, $\mathrm{H}_{2} \mathrm{O}_{2}-K_{0 n z}{ }^{1 / 400}-\mathbf{n}$.

\begin{tabular}{|c|c|c|c|c|c|c|c|c|c|}
\hline & \multicolumn{3}{|c|}{ Ungeschüttelt } & \multicolumn{3}{|c|}{ Geschüttelt } & \multicolumn{3}{|c|}{ Parallelversuch } \\
\hline $0^{\circ}$ & $\begin{array}{r}1^{\prime} \\
3^{\prime} \\
5^{\prime} \\
11^{\prime} \\
20^{\prime}\end{array}$ & $\begin{array}{r}20,33 \\
17,02 \\
14,74 \\
10,30 \\
7,50\end{array}$ & $\begin{array}{l}386 \\
312 \\
259 \\
164\end{array}$ & $\begin{array}{r}1^{\prime} \\
3^{\prime} \\
5^{\prime} \\
11^{\prime} \\
20^{\prime}\end{array}$ & $\begin{array}{r}18,77 \\
15,88 \\
13,34 \\
8,29 \\
4,56\end{array}$ & $\begin{array}{l}363 \\
379 \\
344 \\
288\end{array}$ & & - & \\
\hline $20^{\circ}$ & $\begin{array}{r}1^{\prime} \\
3^{\prime} \\
5^{\prime} \\
10^{\prime} \\
22^{\prime}\end{array}$ & $\begin{array}{r}19,07 \\
16,38 \\
14,30 \\
10,95 \\
5,80\end{array}$ & $\begin{array}{l}330 \\
295 \\
228 \\
230\end{array}$ & $\begin{array}{c}1^{\prime} \\
3^{\prime} \\
5^{\prime} \\
10^{\prime} \\
20^{\prime}\end{array}$ & $\begin{array}{r}21,09 \\
17,41 \\
13,88 \\
8,01 \\
2,17\end{array}$ & $\begin{array}{l}416 \\
492 \\
478 \\
567\end{array}$ & $\begin{array}{r}1^{\prime} \\
3^{\prime} \\
5^{\prime} \\
11^{\prime} \\
17^{\prime} \\
24^{\prime}\end{array}$ & $\begin{array}{r}21,27 \\
17,80 \\
14,53 \\
8,00 \\
4,27 \\
2,67\end{array}$ & $\begin{array}{l}387 \\
440 \\
432 \\
454 \\
291\end{array}$ \\
\hline
\end{tabular}

1) Hier wurde Evakuieren und Schütteln unterbrochen.

daß man die Reaktion zunächst im ruhenden Reaktionsgemisch verfolgt und dann im Vakuum unter Schütteln fortsetzt. Man sieht, wie das Ferment sich dann im zweiten Teil der Reaktion «erholt», indem die ermittelten $\mathrm{K}$-Werte von diesem 
Augenblick des Schüttelns an eine plötzliche Zunahme und einen aufsteigenden Gang zeigen. Diese Versuche wurden mit Fermentlösungen verschiedener Herkunft und verschiedenen Reinheitsgrades vorgenommen, ergaben jedoch qualitativ völlig das gleiche (vgl. Tab. 12).

Tabelle 12. Einfluß des Schüttelns im Vakuum.

$$
\begin{aligned}
& \text { 1. Blutferment } \\
& \mathrm{H}_{2} \mathrm{O}_{2} \text {-Konz. 1/400-n. } 0^{\circ} \text {. }
\end{aligned}
$$

Der Versuch wird unter den gewöhnlichen Bedingungen eingeleitet, nach einigen Entnahmen wird die $\mathrm{H}_{2} \mathrm{O}_{2}$-Kon- lichen Bedingungen eingeleitet, nach zentration wieder auf die ursprüng- einigen Entnahmen wird evakuiert liche Höhe gebracht, evakuiert und geschüttelt

\begin{tabular}{r|r|r|r|r|r}
\hline $1^{\prime}$ & 17,43 & 505 & $1^{\prime}$ & 18,31 & 345 \\
$4^{\prime}$ & 12,30 & 440 & $3^{\prime}$ & 15,62 & 294 \\
$8^{\prime}$ & 8,20 & 416 & $5^{\prime}$ & 13,64 & 298 \\
$18^{\prime}$ & 3,15 & & $8^{\prime}$ & 11,10 & \\
evakuiert und geschüttelt & \multicolumn{3}{|c|}{ evakuiert und geschütte } \\
$1^{\prime}$ & 18,01 & 437 & $10^{\prime}$ & 9,32 & 426 \\
$3^{\prime}$ & 14,73 & 498 & $12^{\prime}$ & 7,66 & 440 \\
$5^{\prime}$ & 11,70 & 528 & $16^{\prime}$ & 5,12 & 554 \\
$10^{\prime}$ & 6,38 & 509 & $23^{\prime}$ & 2,10 & \\
$15^{\prime}$ & 3,55 & & & &
\end{tabular}

War die Wirkung durch die Entfernung des Sauerstoffs verursacht, so mußte umgekehrt vorheriges Sättigen der Fermentlösung mit Sauerstoff eine erhebliche Schwächung zur Folge haben. Dies konnte in der Weise erreicht werden, daß eine gewisse Zeit vor Beginn der Reaktion Sauerstoff durch die Fermentlösung geleitet wurde. Der Effekt ist deutlich und besteht, wie zu erwarten, in einer erheblichen Abnahme der Reaktionsgeschwindigkeit in der vorbehandelten Fermentlösung. ${ }^{1}$ ) Gleichzeitig zeigen die $\mathrm{K}$-Werte dieses Versuchs eine viel bes-

1) Dies steht natürlich nicht mit der von Liebermann und Senter festgestellten Tatsache in Widerspruch, daß sie beim Entfernen des Sauerstoffs aus der Fermentlösung keinen nachteiligen Effekt beobachteten (vgl. Diese Zeitschrift, Bd. 51, S. 699 [1905]). 
șere Konstanz als im Parallelversuch, bei dem kein Durchleiten von Sauerstoff erfolgt war (vgl. Tab.13). Es soll nicht unerwähnt bleiben, daß nach der Auffassung Senters gerade das Gegenteil hätte erwartet werden können. Denn vorherige Sättigung mit Sauerstoff mußte bei Beginn der Reaktion alsbald zu einer lebhafteren Gasentwickelung führen, als im vorher nicht behandelten Reaktionsgemisch: die Gasentwickelung an sich ist offenbar

Tabelle 13. Einfluß des Einleitens von Sauerstoff.

Puppenextrakt von Deilephila euphorbiae. $\mathrm{H}_{2} \mathrm{O}_{2}$-Konz. 1/400-n. $0^{0}$.

\begin{tabular}{|c|c|c|c|c|c|c|c|}
\hline \multicolumn{4}{|c|}{ 1. Ohne Durchleiten von 0} & \multicolumn{4}{|c|}{$\begin{array}{l}\text { 2. Von } 2 \mathrm{~h} 30^{\prime} \text { vor Beginn des Ver- } \\
\text { suchs an wird } 0 \text { durchgeleitet }\end{array}$} \\
\hline \multicolumn{4}{|c|}{ I. } & \multicolumn{4}{|c|}{ I. } \\
\hline & $1^{\prime}$ & 11,80 & & & $1^{\prime}$ & 13,31 & \\
\hline & $3^{\prime}$ & 9,72 & & & $3^{\prime}$ & 11,91 & 241 \\
\hline & $6^{\prime}$ & 7,63 & $\begin{array}{l}351 \\
239\end{array}$ & & $6^{\prime}$ & 10,24 & $\begin{array}{l}219 \\
191\end{array}$ \\
\hline & $16^{\prime}$ & 4,40 & \multirow{2}{*}{137} & & $16^{\prime}$ & 6,59 & \multirow{3}{*}{194} \\
\hline & $26^{\prime}$ & 3,21 & & & $26^{\prime}$ & 4,22 & \\
\hline \multicolumn{4}{|c|}{ II. } & \multicolumn{3}{|r|}{ II. } & \\
\hline$\left(42^{\prime}\right)$ & $1^{\prime}$ & 13,23 & \multirow{4}{*}{$\begin{array}{l}173 \\
191 \\
141\end{array}$} & $\left(37^{\prime}\right)$ & $1^{\prime}$ & 12,95 & \multirow{4}{*}{$\begin{array}{l}201 \\
197 \\
146\end{array}$} \\
\hline$\left(\check{\partial} 2^{\prime}\right)$ & $11^{\prime}$ & 8,88 & & $\left(45^{\prime}\right)$ & $9^{\prime}$ & 8,15 & \\
\hline$\left(62^{\prime}\right)$ & $21^{\prime}$ & 5,72 & & $\left(57^{\prime}\right)$ & $21^{\prime}$ & 5,18 & \\
\hline$\left(82^{\prime}\right)$ & $41^{\prime}$ & 2,97 & & $\left(77^{\prime}\right)$ & $41^{\prime}$ & 2,65 & \\
\hline \multicolumn{4}{|c|}{ III. geschüttelt und evakuiert } & \multicolumn{4}{|c|}{ III. geschüttelt und evakuiert } \\
\hline$\left(126^{\prime}\right)$ & $1^{\prime}$ & 18,30 & \multirow{5}{*}{$\begin{array}{l}187 \\
313 \\
367 \\
366\end{array}$} & $\left(86^{\prime}\right)$ & $2^{\prime}$ & 15,75 & \multirow{5}{*}{$\begin{array}{l}273 \\
288 \\
327 \\
317\end{array}$} \\
\hline$\left(130^{\prime}\right)$ & $5^{\prime}$ & 15,40 & & $\left(90^{\prime}\right)$ & $6^{\prime}$ & 12,25 & \\
\hline$(\mathbf{1 3 5})$ & $10^{\prime}$ & 10,74 & & $(95)$ & $11^{\prime}$ & 8,79 & \\
\hline$\left(143^{\prime}\right)$ & $18^{\prime}$ & 5,46 & & $\left(102^{\prime}\right)$ & $18^{\prime}$ & 5,19 & \\
\hline$\left(151^{\prime}\right)$ & $26^{\prime}$ & 2,78 & & $\left(112^{\prime}\right)$ & $28^{\prime}$ & 2,50 & \\
\hline
\end{tabular}

ohne irgend welche Bedeutung für den Reaktionsverlauf. Daß die: Abnahme der Reaktionsgeschwindigkeit wirklich durch die Sauer-. stoffadsorption verursacht, also eine reversible war, konnte leicht: gezeigt werden, indem man das Reaktionsgemisch während der' Reaktion im Vakuum schüttelte. Zugleich begannen die Kon-stanten zuerst schnell, dann langsam zu steigen auf Werte, die: 
nicht wesentlich von den Anfangswerten der unter normalen Bedingungen eingeleiteten Reaktion abwichen. Das schon sehr geschwächte Ferment hatte also durch diese Behandlung seine anfängliche Aktivität zurückerhalten.

Es schien unter diesen Umständen wichtig, zu entscheiden, ob das Ferment auch durch Einleiten anderer Gase geschwächt wird. Wie der Versuch zeigt, scheint Stickstoff einen ähnlichen Effekt zu haben wie Sauerstoff, wenn auch schwächer. Auch dieser Befund scheint uns für die Richtigkeit unserer Annahmen zu sprechen. Es war unwahrscheinlich, daß ein vorhandenes Adsorptionsvermögen ausschließlich auf wenig bestimmte Stoffe von Einfluß sein würde. Anderseits ist dadurch, daß auch ein so indifferentes Gas wie Stickstoff eine schwächende Wirkung auf die Fermentaktivität ausübt, wiederum gezeigt, daß diese nicht mit einem Oxydationsvorgang in Zusammenhang stehen kann (vgl. Tab. 14).

Tabelle 14. Einfluß gelöster Gase.

Blutferment. $\mathrm{H}_{8} \mathrm{O}_{2}$-Konz. ${ }^{1 / 400-n .} 0^{\circ}$.

\begin{tabular}{|c|c|c|c|c|c|c|c|c|c|c|c|}
\hline \multicolumn{3}{|c|}{$\begin{array}{c}\text { 1. } \mathrm{CO}_{2} \text {-haltig } \\
\text { sofort untersucht }\end{array}$} & \multicolumn{3}{|c|}{$\begin{array}{l}\text { 2. } \mathrm{CO}_{2} \text {-haltig } \\
\text { nach } 5 \text { Std. Stehen } \\
\text { untersucht }\end{array}$} & \multicolumn{3}{|c|}{$\begin{array}{l}\text { 3. Stickstoff } \\
\text { \& Std. durch- } \\
\text { geleitet }\end{array}$} & \multicolumn{3}{|c|}{$\begin{array}{l}\text { 4. Sauerstoff } \\
3 \text { Std. } 30 \text { Min. } \\
\text { durchgeleitet }\end{array}$} \\
\hline $1^{\prime}$ & & & 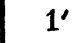 & & & $1^{\prime}$ & 16,75 & & $1^{\prime}$ & 17 & \\
\hline $4^{\prime}$ & 10,30 & & $\Psi^{\prime}$ & 12,42 & & $4^{\prime}$ & 13,12 & & $4^{\prime}$ & 18 & \\
\hline $9^{\prime}$ & 5 & & $9^{\prime}$ & 8, & & $9^{\prime}$ & 9 , & & $9^{\prime}$ & 10,12 & \\
\hline $18^{\prime}$ & 2,39 & & $14^{\prime}$ & 5,55 & & $19^{\prime}$ & 4,79 & & $19^{\prime}$ & 5,35 & \\
\hline
\end{tabular}

Mit Rücksicht auf das Gesagte erscheinen nun auch die früher beschriebenen Verdünnungsversuche in einem anderen Lichte. Die Verdünnung der Fermentlösung geschah immer mit kohlensäurehaltigem Wasser, und es war gezeigt worden, daß kohlensäurefreies Wasser keine solche Wirkung hervorruft. Auch hier kann man eine Adsorptionswirkung durch den Kohlensäuregehalt annehmen. Natürlich aber darf nicht außer acht gelassen werden, daß bei den Versuchen mit einem säureliefernden Gas auch die sich bildenden Wasserstoffionen verzögernd wirken werden. Doch dürfte wohl die ganz enorm starke 
Schwächung, die eine Fermentlösung beim Durchleiten von Kohlensäure während der Reaktion erfährt (vgl. I. Mitteilung, S. 273), darauf zurückzuführen sein, daß auch hier die Absorption des Gases neben der Acidität eine wesentliche Rolle spielt.

Daß es sich schließlich hier wirklich um spezifische Eigenschaften der kolloiden Fermentlösungen handelt, wird noch besonders klar, wenn man vergleichende kinetische Messungen auf gasvolumetrischem Wege mit kolloiden und nichtkolloiden Lösungen als Katalysatoren ausführt. Während es bei der Jodionenkatalyse ${ }^{1}$ ) des Hydroperoxyds für die zu messende Reaktionsgeschwindigkeit durchaus ohne Bedeutung ist, ob das Reaktionsgemisch vor dem Versuch mit Sauerstoff gesättigt wird oder nicht, ist die Vorbehandlung des Reaktionsgemisches mit Sauerstoff bei der Fermentkatalyse von entscheidender Bedeutung, sowohl mit Rücksicht auf die Reaktionsgeschwindigkeit als auf den Reaktionsverlauf. Bei mit Sauerstoff vorbehandelter Fermentlösung sinkt die Gesamtreaktionsgeschwindigkeit infolge einer partiellen Inaktivierung des Ferments durch den Sauerstoff, dafür verschwindet aber der bei der nicht vorbehandelten Fermentlösung trotz intensiver Rührung des Reaktionsgemischs auftretende Gang, weil der sich entwickelnde Sauerstoff jetzt entsprechend dem wirklichen Fortschritt der Reaktion ziemlich vollständig abgegeben werden kann (vgl. Tab.15a u.b). Besonders interessant und beweisend für die Richtigkeit unserer Auffassung erscheinen auch einige weitere gasvolumetrische Messungen am ruhenden Reaktionsgemisch. Wählt man eine nicht zu hohe Fermentkonzentration und die Peroxydkonzentration derart, daß auch in der ruhenden Flüssigkeit eine schwache Gasentwicklung einsetzt, so wird nach Beendigung der Reaktion durch Rühren sämtlicher Sauerstoff ausgetrieben. Erhöht man nun ceteris paribus die Fermentkonzentration auf das Doppelte, so sollte man infolge der Steigerung der Reaktionsgeschwindigkeit eine

1) Die Jodionenkatalyse des Hydroperoxyds ist bekanntlich von Walton, einem Schüler G. Bredigs, eingehend untersucht worden (Zeitschr. f. physikal. Chem., Bd. 47 (1904), S. 185). 
lebhaftere Gasentwicklung erwarten, aber es ist genau das Gegenteil der Fall. Die Gasentwicklung unterbleibt ganz. Die Erklärung ergibt sich, wenn nach Beendigung der Reaktion, der durch Rühren austreibbare Sauerstoff gemessen wird: Es gelingt jetzt nicht mehr, ihn vollständig aus der Lösung zu entfernen, da offenbar ein Teil zu stark von dem adsorbierenden Ferment festgehalten wird. Und diese stärkere Adsorption bedingt offenbar auch das Ausbleiben jeder spontanen Gasentwicklung (vgl. Tab. 6).

Tabelle 15 a. Gasvolumetrische Messung der Jodionenkatalyse und der Fermentkatalyse des $\mathrm{H}_{2} \mathrm{O}_{2}$.

a) Jodionenkatalyse nach Walton.

\begin{tabular}{|c|c|c|c|c|c|}
\hline \multicolumn{3}{|c|}{ Ohne Durchleiten von $\mathrm{O}_{2}$} & \multicolumn{3}{|c|}{$\begin{array}{l}\text { Vor Beginn des Versuchs } \mathrm{O}_{2} 30^{\prime} \text { unter } \\
\text { Rühren durch die Lösung geleitet }\end{array}$} \\
\hline Zeit & $\begin{array}{l}\mathrm{O}_{2} \text { entw. } \\
\text { in } \mathrm{ccm}\end{array}$ & $\mathbf{K}$ & Zeit & $\begin{array}{l}\mathrm{O}_{2} \text { entw. } \\
\text { in } \mathrm{ccm}\end{array}$ & $\mathrm{K}$ \\
\hline $\begin{array}{r}3^{\prime} \\
7^{\prime} \\
11^{\prime} \\
15^{\prime} \\
20^{\prime} \\
25^{\prime} \\
30^{\prime}\end{array}$ & $\begin{array}{r}3,7 \\
9,4 \\
14,9 \\
20,7 \\
27,0 \\
33,3 \\
39,3\end{array}$ & $\begin{array}{l}400 \\
400 \\
423 \\
410 \\
417 \\
419 \\
\left.: 411^{1}\right)\end{array}$ & $\begin{array}{r}2^{\prime} \\
5^{\prime} \\
8^{\prime} \\
11^{\prime} \\
14^{\prime} \\
17^{\prime}\end{array}$ & $\begin{array}{r}4,6 \\
13,9 \\
22,6 \\
31,1 \\
39,6 \\
47,4\end{array}$ & $\begin{array}{l}416 \\
400 \\
404 \\
410 \\
403\end{array}$ \\
\hline
\end{tabular}

Obne Durchleiten von $\mathrm{O}_{2}$

\begin{tabular}{r|r|r|r|r|r}
$5^{\prime}$ & 0,5 & - & $1^{\prime}$ & 0,9 & 116 \\
$14^{\prime}$ & 2,2 & 87,6 & $5^{\prime}$ & 3,9 & 130 \\
$23^{\prime}$ & 6,3 & 147 & $13^{\prime}$ & 9,5 & 128 \\
$28^{\prime}$ & 9,5 & 150 & $18^{\prime}$ & 12,9 & 129 \\
$41^{\prime}$ & 15,8 & 150 & $24^{\prime}$ & 15,4 & 131 \\
$53^{\prime}$ & 20,2 & 183 & $45^{\prime}$ & 22,5 & \\
$109^{\prime}$ & 24,7 & 186 & & &
\end{tabular}

1) Aus Waltons Angaben berechnet sich für dieselben Versuchsbedingungen (vgl. Diese Zeitschrift, Bd. 47, S. 193) als Mittelwert für K: 410 . 
Tabelle 15b. Vergleich titrimetrisch verfolgter Reaktion (ruhende Flüssigkeit, keine Vorbehandlung mit Sauerstoff) mit derselben Reaktion gasvolumetrisch gemessen (mit $\mathrm{O}_{2}$ vorbehandelt).

$$
1 / 100-\mathrm{n}-\mathrm{H}_{2} \mathrm{O}_{2} .0^{0} \text {. }
$$

a) Titrimetrisch, ohne Vorbehandlung mit Sauerstoff, ohne Rührung

\begin{tabular}{r|r|r|r|r|r}
\hline $1^{\prime}$ & 15,65 & 508 & $1^{\prime}$ & 1,4 & 366 \\
$3^{\prime}$ & 12,39 & 455 & $3^{\prime}$ & 6,6 & 336 \\
$6^{\prime}$ & 9,08 & 407 & $6^{\prime}$ & 11,8 & 381 \\
$10^{\prime}$ & 6,22 & 331 & $9^{\prime}$ & 16,1 & 341 \\
$15^{\prime}$ & 4,25 & 269 & $13^{\prime}$ & 20,3 & 352 \\
$21^{\prime}$ & 2,93 & & $18^{\prime}$ & 24,1 &
\end{tabular}

Zusammenfassend läßt sich jedenfalls aus dem Vorangegangenen folgern, daß die Adsorptionsvorgänge mit Erfolg zur Erklärung gewisser Eigentümlichkeiten der fermentativen Hydroperoxydzersetzung herangezogen werden können. Es fragt sich jedoch, ob alle Eigentümlichkeiten dieser Reaktion eine ausreichende Deutung durch die Betrachtungsweise finden können.

Nach den bisherigen Annahmen wäre immer dann, wenn die Reaktion unter Schütteln im Vakuum vorgenommen würde, ein aufsteigender Gang der K-Werte entsprechend der angenommenen Hydroperoxydadsorption oder mindestens eine Konstante zu erwarten. Dies ist nun bei den Versuchen mit Raupenferment jedoch durchaus nicht der Fall. Allerdings wird durch die obige Versuchsanordnung die Reaktionsgeschwindigkeit ganz allgemein wesentlich erhöht und ebenso der absteigende Gang stark verringert, ein Verschwinden des Ganges ist jedoch nicht festzustellen. Es muß also entweder die Entfernung des sich entwickelnden Sauerstoffs ungenügend sein oder es muß noch ein anderer Grund für den Gang vorliegen, sodaß dieser sich durch die bloßen obigen Maßnahmen nicht beseitigen läßt. Nun kann gesagt werden, daß die erste Annahme mit Sicherheit zutreffen wird. Schon die Unvollkommenheit der Versuchsanordnung, die darin liegt, daß zur Titerentnahme stets das Vakuum aufgehoben und die Schüttelwirkung unterbrochen werden muß, spricht dafür. Dazu kommt, daß der sich ja in 
unmittelbarer Nähe der Fermentteilchen entwickelnde Sauerstoff mit äußerster Leichtigkeit von diesen wird adsorbiert werden können. Dies stimmt durchaus mit der Tatsache, die der eine von uns bei gasvolumetrischen Versuchen fand, überein, daß die Gasübersättigung in solchen Fermentlösungen viel höher getrieben werden kann, wenn man den Sauerstoff sich im Reaktionsgemisch entwickeln läßt, als wenn man ihn in feinen Bläschen in die Lösung einleitet. Berücksichtigt man ferner die Tatsache, daß bei Körpern mit großer Oberflächenentwicklung das Adsorptionsgleichgewicht so zugunsten der dispersen Phase verschoben ist, daß mit Hilfe einer solchen Anordnung die höchsten Vakua erzielt werden können, so erscheint es umgekehrt durchaus unwahrscheinlich, daß es durch einfaches Evakuieren des Reaktionsgemischs an der Wasserstrahlpumpe gelingen sollte, die Adsorption des Sauerstoffs an den Kolloidteilchen vollständig $\mathrm{zu}$ verhindern. Um diese Frage $\mathrm{zu}$ entscheiden, müßten Versuche mit einer wirksameren Versuchsanordnung ausgeführt werden.

Tabelle 16. Einfluß der Fermentmenge auf die Sauerstoffentwicklung.

$\mathrm{H}_{2} \mathrm{O}_{2}$-Konz. ca. ${ }^{1 / 100-n} .0^{0}=$ ca. $24 \mathrm{ccm} \mathrm{O}_{2}$.

\begin{tabular}{|c|c|c|c|}
\hline & a) & \multicolumn{2}{|c|}{ b) Parallelversuch } \\
\hline \multirow{4}{*}{$\begin{array}{c}\text { Fer- } \\
\text { ment- } \\
\text { konz. } 1\end{array}$} & \multirow{4}{*}{$\begin{array}{l}\text { Ruhende Flüssigkeit: In } 60^{\prime} \text { entwick. } 1,8 \mathrm{~cm} \mathrm{O}_{2} \\
\text { Darauf durch Rühren ausgetrieben } 15,7 \text {, } \\
\text { Unzersetzter } \mathrm{H}_{2} \mathrm{O}_{2} \text {, entsprechend } \frac{7,3,}{\text { Summe } \cdot .24,8 \mathrm{~cm} \mathrm{O}_{2}} \\
\text { Also aller Sauerstoff ausgetrieben. }\end{array}$} & \multirow[t]{3}{*}{$100^{\prime}$} & $1,9 \mathrm{ccm} \mathrm{O}_{2}$ \\
\hline & & & 1,0 Cin $U_{2}$ \\
\hline & & & 11,4 \\
\hline & & \multicolumn{2}{|c|}{$\begin{array}{l}\text { Also fast aller Sauer- } \\
\text { stoff ausgetrieben. }\end{array}$} \\
\hline \multirow{3}{*}{ Fer- } & \multirow{2}{*}{ RuhendeFilüssigkeit: $\ln 80^{\prime}$ entwickelt $0,2 \mathrm{ccm} \mathrm{O}_{4}$} & \multicolumn{2}{|r|}{ b) } \\
\hline & & \multirow[t]{2}{*}{$90^{\prime}$} & $0,1 \mathrm{ccm} \mathrm{O}_{2}$ \\
\hline & Darauf durch Rühren ausgetrieben . 8,3 , > & & 11,4 , \\
\hline ment- & Unzersetzter $\mathrm{H}_{2} \mathrm{O}_{2}$, entsprechend $.0,0$, & \\
\hline konz. 2 & Summe . . $\overline{8,5 \mathrm{ccm} \mathrm{O}}$ & \multicolumn{2}{|r|}{$11,7 \mathrm{ccm} \mathrm{O_{2 }}$} \\
\hline . & Also ca. $15,5 \mathrm{ccm} \mathrm{O}_{2}$ in der Lösung zurück- & \multicolumn{2}{|c|}{$\begin{array}{l}\text { Also ca. } 12,3 \mathrm{ccm} \mathrm{O}_{2}^{\prime} \\
\text { in der Lösung } \\
\text { zurückgehalten. }\end{array}$} \\
\hline
\end{tabular}


Daß auch bei Zimmertemperatur eine Sauerstoffadsorption stattfindet, läßt sich leicht auf dieselbe Art feststellen, wie dies bei $0^{\circ}$ geschehen ist. Führt man die Reaktion im ruhenden Reaktionsgemisch aus und schüttelt dann dasselbe in einer späteren Phase der Reaktion eine Zeitlang kräftig durch, so erhält man ebenso wie bei $0^{0}$ eine Zunahme der Reaktionsgeschwindigkeit, die ganz beträchtlich sein kann. Noch viel deutlicher wird dies, wenn man zur Entfernung des Sauerstoffs das Vakuum zu Hilfe nimmt (vgl. Tab. 12).

\section{Einfluß der Temperatur.}

Nach dem Vorangegangenen ist es uns daher auch nicht möglich, uns der Senter schen Auffassung über den Einfluß der Temperaturerhöhung des Reaktionsgemisches auf die Reaktion völlig anzuschließen. Er hält einen normalen Temperaturkoeffizienten von 1,5 pro $10^{\circ}$ Temperaturdifferenz wenigstens für das Intervall von $0-10^{\circ}$ für erwiesen. Und diese Tatsache bildet die stärkste Stütze seiner Diffusionstheorie. Denn in einer Diskussion mit Euler hat er sie als sicheren Beweis dafür hingestellt, daß die gemessene Reaktionsgeschwindigkeit einer chemischen Reaktion nicht entsprechen kann. Stimmen wir auch hierin mit Senter vollständig überein, so müssen wir es doch als nicht berechtigt erklären, den Temperaturkoeffizienten der Reaktion auf einen bestimmten Wert festzulegen, der mit den Reaktionskoeffizienten von Vorgängen im makroheterogen System irgendwie in Parallele zu setzen wäre. Es läßt sich in Wahrheit kein bestimmter Wirkungsbetrag angeben, sondern der Temperaturkoeffizient schwankt (vgl. I. Mitteilung) im weiten Maße nach oben und unten um den Wert 1,2 für das Temperaturintervall von $10^{\circ}$, liegt jedoch fast in der größeren Zahl der Fälle unter dem von Senter festgelegten Werte.

Wir haben früher Versuche bei $30^{\circ}$ mitgeteilt und Senter hat die Ansicht ausgesprochen, daß sie unzuverlässig seien, weil bei so hohen Temperaturen Komplikationen eintreten könnten, die wir nicht berücksichtigt hätten. Es ist deshalb bei unseren neuen Versuchen diese Reaktionstemperatur nicht mehr ausschließlich in Betracht gezogen worden. Es läßt sich aber jeden- 
falls beweisen, daß bis zur Reaktionstemperatur von $20^{\circ}$ bei niedriger Peroxydkonzentration keine Erscheinungen eintreten, welche Senters Mißtrauen rechtfertigen, Wenn man nämlich die Möglichkeit erörtert, welche den kleinen Temperaturkoeffizienten der Reaktion veranlassen könnten, so wird man diese zunächst in einer irgendwie verursachten raschen Zerstörung des Ferments bei höherer Temperatur zu suchen haben. Nun ist es ja hinreichend bekannt, daß das Ferment tatsächlich bei höherer Temperatur allmählich zerstört wird. Diese Zerstörungsgeschwindigkeit liegt jedoch weit unter derjenigen, welche erforderlich wäre, den niedrigen Temperaturkoeffizienten zu erklären. Man müßte also auch hier auf eine Mitwirkung des Peroxyds dabei zurückkommen und annehmen, daß das Ferment momentan bei höherer Temperatur $\left(20^{\circ}\right)$ auf irgend eine Weise in Gegenwart des Peroxyds geschwächt würde. Dagegen sprechen nun durchaus die nachstehend mitgeteilten Versuche, in denen die Temperatur stufenweise um immer $5^{\circ}$ von $0^{\circ}-20^{\circ}$ erhöht wurde. Es wäre zu erwarten gewesen, daß, wenn bei höherer Temperatur die Zerstörung merklicher in Betracht käme, der Temperaturkoeffizient der Reaktion, innerhalb eines tiefgelegenen Temperaturintervalls gemessen, bedeutend größer wäre, als etwa zwischen $15^{\circ}$ und $20^{\circ}$. Davon ist jedoch durch-

Tabelle 17. Einfluß der Temperatur.

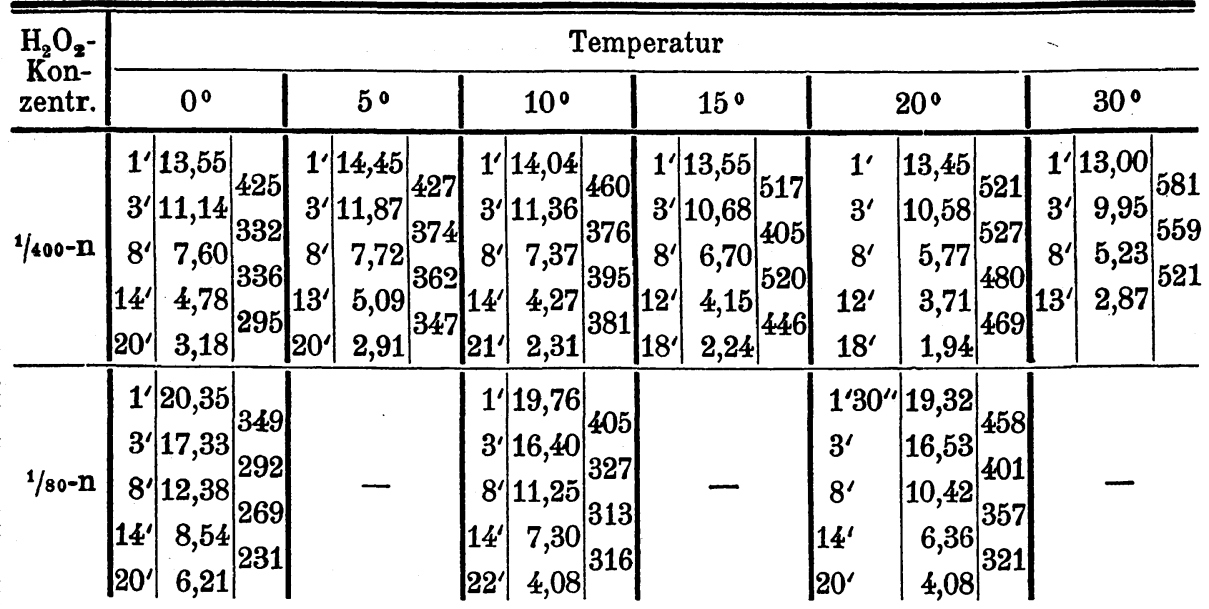

Hoppe-Seyler's Zeitschrift f. physiol. Chemie. LXXIX. 
aus nichts zu bemerken. Vielmehr steigen die Anfangs-K-Werte von $5^{0} \mathrm{zu} 5^{0}$ ziemlich regelmäßig um den ungefähr gleichen geringen Betrag, und gleichzeitig tritt die früher schon geschilderte Verbesserung der Konstanz der K-Werte in deutlicher Weise hervor. Und was besonders bemerkenswert ist, fast genau die gleichen Verhältnisse gelten für eine bedeutend höhere Hydroperoxydkonzentration im Reaktionsgemisch. Allerdings liegen die Anfangs-K-Werte hier wiederum (vgl. Tab. 3) wesentlich tiefer als bei den 1/400-n-Versuchen. Aber dies ist nach der Adsorptionstheorie durchaus verständlich. Denn vergleicht man die Anfangs$\mathrm{K}$-Werte für beide Reaktionsarten, die gleichen Zeitintervallen entsprechen, so ist es klar, daß bei der fünffach höheren Peroxydkonzentration im Reaktionsgemisch ungefähr die fünffach größere Menge Sauerstoff in Freiheit gesetzt wird, die natürlich eine entsprechend stärkere Wirkung auf das Ferment entfalten muß. Wir bestätigen also damit den Senterschen Befund, daß bei höherer Peroxydkonzentration die Konstanten etwas niedriger liegen, halten diese Tatsache jedoch verursacht durch eine gesteigerte Adsorption des gelösten Sauerstoffes, nicht, wie Senter glaubt, durch die Wirkung der Sauerstoffbläschen (vgl. Tab. 17).

Daß keine sehr schnelle Schwächung des Ferments durch die Wirkung des Peroxyds bei höherer Temperatur eintritt, wenn dessen Konzentration nur niedrig gehalten wird, geht übrigens ferner daraus hervor, daß, wenn man die Reaktion nur kurze Zeit bei höherer Temperatur verfolgt, um dann das Reaktionsgemisch auf $0^{\circ} \mathrm{zu}$ bringen, die bei dieser Temperatur gefundenen $\mathrm{K}$-Werte nun keineswegs tiefer liegen als diejenigen, welche nach der gleichen Zeit erhalten wurden, wenn der Versuch von Anfang bei $0^{\circ}$ ausgeführt wurde (vgl. Tab. 18).

Etwas anders scheinen die Verhältnisse zu liegen bei gleichzeitiger Erhöhung der Peroxydkonzentration. Vergleicht man die Versuche mit 1/80-n-Lösungen mit denen bei 1/400-nPeroxyd, so fällt es auf, daß die Verbesserung der Konstanz bei höherer Temperatur nicht mehr zu beobachten ist, sondern der Gang hier unverändert bleibt (vgl. Tab. 3). Dies wäre nun allerdings schon einigermaßen durch die gesteigerte Sauerstoffentwicklung bei höheren Peroxydkonzentrationen zu erklären, 
Tabelle 18. Einfluß der Temperatur.

Blutferment, $\mathrm{H}_{2} \mathrm{O}_{2}{ }^{1 / 400-n}$.

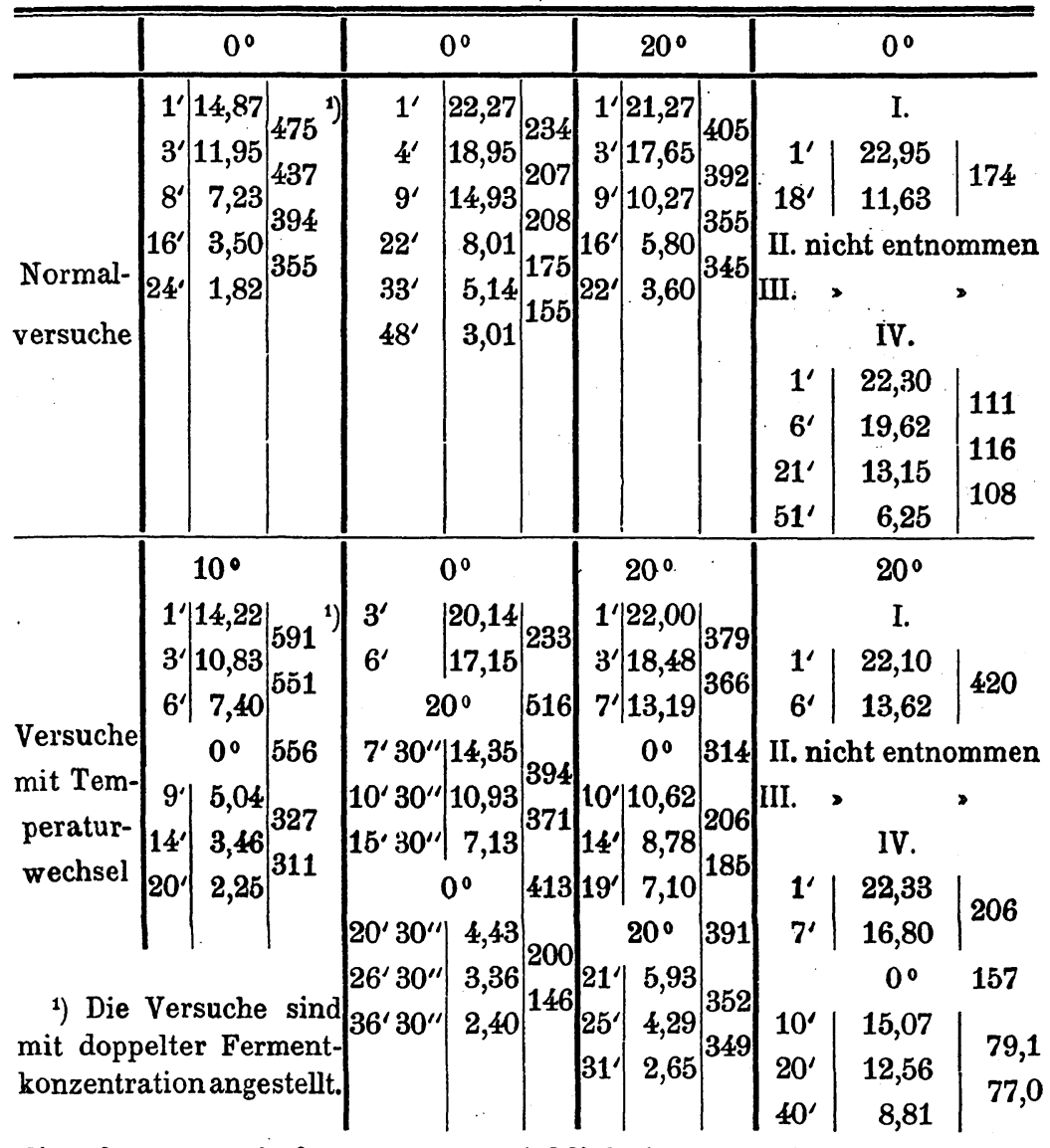

die eben von Anfang an zu reichlich ist, um einen merkbaren Einfluß der Temperaturerhöhung beobachtbar zu machen. Jedoch sprechen die mitgeteilten Versuche mit Temperaturwechsel dafür, daß bei höherer Untersuchungstemperatur allmählich auch eine direkte zerstörende Wirkung auf das Ferment ausgeübt wird, die nichts mit den reversiblen Adsorptionswirkungen zu tun hat. Läßt man nämlich das Ferment längere Zeit bei $20^{\circ}$ auf das Peroxyd einwirken und verfolgt die Reaktion darauf bei $0^{0}$ weiter, so ergibt sich, daß die jetzt gefundenen K-Werte verglichen mit denen einer Reaktion, die ebenso lange Zeit nur 
bei $0^{\circ}$ vor sich gegangen ist, erheblich tiefer liegen (vgl. Tab. 18). $\mathrm{Ob}$ dieser Erscheinung ein Oxydationsvorgang zugrunde liegt, läßt sich nicht beweisen, jedoch läßt sich die allmähliche Schwächung des Ferments während der Reaktion, welche sich unter diesen Bedingungen über die Adsorptionsvorgänge zu lagern scheint, wohl so erklären.

7. Einfluß der Fermentkonzentration.

Senter hat seine aKonvektionstheorie noch auf andere Weise, wie anfangs erwähnt wurde, zu stützen gesucht. In seiner ersten Arbeit beschreibt er einige Versuche über den Einfluß der Fermentkonzentration auf die Reaktionsgeschwindigkeit, die ihn zu der Annahme führen, daß die Reaktionsgeschwindigkeit bei höherer Fermentkonzentration und Peroxydkonzentration rascher als proportional der Fermentkonzentration anwachse. Er zieht daraus den Schluß, daß hier ähnliche Verhältnisse vorliegen, wie bei der von Bredig und seinen Mitarbeitern untersuchten Platinkatalyse, bei der allerdings ein mit wachsender Fermentkonzentration sehr erhebliches Ansteigen der Reaktionsgeschwindigkeit über das Verhältnis der Proportionalität hinaus beobachtet wurde. Die Erklärung für diese Tatsache ist nach Senter in zwei Erscheinungen gegeben, die für die Katalase ebenso wie für die Platinkatalyse in Betracht kommen sollen, nämlich einmal in der bei hohen Fermentkonzentrationen ceteris paribus stärkeren Sauerstoffentwicklung, die wiederum eine kräftige Durchrührung, mithin Abkürzung des Diffusionsweges bedingen soll; zweitens in einer Zunahme des Rühreffekts durch die Brownschen Bewegungen der Kolloidteilchen. Die letztere Annahme entspricht der von Bredig und seinen Mitarbeitern zur Erklärung des Verhaltens der Platinkatalyse gemachten. Sie ist auch hier durchaus plausibel. Denn unter bestimmten Annahmen über die Beziehungen zwischen Reaktionsgeschwindigkeit, Rührgeschwindigkeit und Platingehalt kann man die zu erwartenden K-Werte aus dem Platingehalt des Reaktionsgemisches berechnen und findet dann relativ sehr gute Übereinstimmung zwischen berechneten und experimentell gefundenen Werten (vgl. hierüber Freundlich, Kapillarchemie, S. 328). 
Was nun die Übertragung dieser Auffassung auf die fermentative Hydroperoxydzersetzung anlangt, so ist mit Bezug auf den Einfluß der Rührung durch die Sauerstoffbläschen sicherlich richtig, daß diese bei höherer Konzentration von Ferment und Peroxyd in stärkerem Maße in Betracht kommt. Dies zeigt schon der Augenschein, wenn man die Gasentwicklung des ruhenden Reaktionsgemisches ceteris paribus einmal bei niederer, das andere Mal bei einer höheren Ferment- oder Peroxydkonzentration betrachtet.

Man könnte allerdings, wenn man sich die Anschauungsweise von Senter zu eigen macht, einwenden, daß die mit wachsender Fermentkonzentration gesteigerte Sauerstoffbläschenbildung ja anderseits auch die Diffusionsoberfläche verkleinern und dadurch die Reaktionsgeschwindigkeit im entsprechenden Maße ungünstig beeinflussen müsse. Dagegen ist aber zu sagen, daß ja über den Betrag der beiden Wirkungen sich nichts voraussagen läßt und daher auch die Resultate der beiden entgegengesetzten Einflüsse nicht von vornherein zu bestimmen ist, daß aber vor allem ja für die störende Wirkung das Verhältnis von Kolloidteilchenzahl zu Sauerstoffbläschenzahl in Betracht kommen wird, und daß dies ja tatsächlich bei einer Fermentgehaltserhöhung keine Änderung erfahren wird. ¿Die auf S. 483 beschriebenen Versuche sprechen jedoch gegen eine solche Wirkung. Denn anstatt die spontane Gasentwicklung zu erhöhen, vermindert die Erhöhung der Fermentkonzentration diese bis zum völligen Rückstand. Wie liegen nun die Verhältnisse mit Rücksicht auf die Annahme, daß die Brownschen Bewegungen hier wesentlich ins Gewicht fallen sollen? Zwischen dem Platinsol und der Katalase besteht der wesentliche Unterschied, daß ersteres ein Suspensionskolloid, und letzteres ein sogenanntes hydrophiles Kolloid darstellt und daß die Brownschen Bewegungen der ersteren zwar (vgl. hierüber vor allem die Angaben bei Svedberg über das Platinsol, Zeitschr. für Elektr. Chemie, Bd. 12, S. 883 [1906]), nicht aber diejenigen der hydrophilen Kolloide genügend bekannt sind. So sagt Freundlich in seinem Lehrbuch seingehende Untersuchungen der Brownschen Bewegung bei Emulsionskolloiden liegen nicht vor» und 
fügt hinzu, daß in denjenigen Fällen, wo die gesonderten Teilchen eines Emulsionskolloids im Ultramikroskop wahrnehmbar sind, ihre Bewegungen zweifellos träger sind, als diejenigen der Suspensionskolloide. Wir haben bei Betrachtung unserer Fermentlösungen im Ultramikroskop Submikronen beobachten können, die deutliche, wenn auch schwache Bewegungen ausführten. Es ist jedoch natürlich schwer zu sagen, ob die beobachteten Teilchen wirklich mit den Fermentteilchen identisch sind und nicht von den stets anwesenden, nicht ausschließbaren Verunreinigungen mit anderen Kolloiden herrühren. Es ließen sich da wohl nur aus einer großen Anzahl vergleichender Versuche Schlüsse ziehen, wie ja überhaupt eine sorgfältige ultramikroskopische Untersuchung der Fermentlösungen noch manche Aufklärung über ihre Eigenschaften zu geben verspricht.

Ist danach also auch das Vorhandensein Brownscher Bewegungen bei den Fermentteilchen möglich, so gewinnt doch die Annahme, daß sie eine wesentliche Rolle in dem Sinne spielen sollten, daß sie bei irgend einer von außen bewirkten Veränderung ihrer Intensität den Diffusionsweg abkürzen und damit die Reaktionsgeschwindigkeit erhöhen sollten, nicht an Wahrscheinlichheit, wenn man die Wirkung der Temperatur auf die Reaktionsgeschwindigkeit berücksichtigt. Denn es ist nicht einzusehen, weshalb nicht auch die im übrigen mit Sicherheit festgestellte Beschleunigung der Brownschen Bewegungen ${ }^{1}$ ) durch Temperaturerhöhung ebenfalls auf die wesentliche Durchrührung des Reaktionsgemisches wirken und dadurch eine merkliche Beschleunigung der Reaktion mit wachsender Temperatur hervorrufen sollte. Es ist ja aber eben dargelegt worden, daß der Temperatureinfluß zweifellos bei den Katalasereaktionen viel geringer ist als bei der Platinkatalyse.

Es fragt sich nun zunächst einmal, ob überhaupt die Voraussetzungen für die Annahme Senters als zutreffend bezeichnet werden können, d. h. ob es die Regel ist, daß bei höherer Fermentkonzentration die Tendenz vorhanden ist, daß

1) Nach Exner steigt bei Suspensionskolloiden zwischen 20 und $70^{\circ}$ das Quadrat der Geschwindigkeit der Brownschen Bewegung geradlinig mit der Temperatur. 
die Reaktionsgeschwindigkeit schneller als proportional der Fermentkonzentration wächst.

Schon aus früheren Versuchen konnten wir eine solche Folgerung nicht ziehen. Zwar läßt sich in den meisten Fällen eine völlige Proportionalität zwischen Fermentkonzentration und Reaktionsgeschwindigkeit nicht feststellen. Doch lagen die $\mathrm{Ab}$ weichungen schon bei unseren früheren Versuchen gerade in entgegengesetzter Richtung, als Senter vermutet, $d . h$. bei hoher Fermentkonzentration nahmen die Geschwindigkeiten meist etwas langsamer zu als proportional der Fermentkonzentration.

Wir haben nun diese Versuche noch einmal in einem möglichst großen Konzentrationsintervall wiederholt, indem wir die K-Werte Senters nach oben und unten überschritten und auch die Versuchsbedingungen bezüglich der Hydroperoxydkonzentration und der Reaktionstemperatur variierten. Die Ergebnisse finden sich in der folgenden Tabelle verzeichnet (Tab. 19). Von einem schnelleren Anwachsen der K-Werte als proportional der Fermentkonzentration ist nichts festzustellen, obgleich die Fermentkonzentration in manchen Fällen um das Vierzigfache, in anderen wenigstens um den 24 fachen Betrag variierte. Am besten ist Proportionalität bei $20^{\circ}$ in $1 / 400$-Lösungen gewahrt. In den anderen Fällen bei tieferen Temperaturen und bei demselben bzw. höheren Peroxydgehalt treten Abweichungen in dem Sinne ein, daß gerade eine Verlangsamung der Reaktion bei höherer Fermentkonzentration gefolgert werden muß, wenigstens wenn man die Anfangswerte der Reaktionen miteinander vergleicht. Es würde jedoch ungerechtfertigt erscheinen, aus dieser Tatsache irgend welche andere Folgerungen zu ziehen, als die, daß wiederum hier die Adsorptionsvorgänge störend ins Gewicht fallen. Denn wenn man den Reaktionsverlauf in dem einen und anderen Fall vergleicht, so ist deutlich, daß in dem Versuch mit geringerer Fermentkonzentration infolge der in der Zeiteinheit geringeren Sauerstoffentwicklung die Adsorption erst nach und nach zur Wirkung kommt, während bei hoher Fermentkonzentration die größere Konstanz der $\mathrm{K}$-Werte zeigt, daß schon die ersten K-Werte wesentlich durch die Sauerstoffadsorption beeinträchtigt sind. Vergleicht man die Konstanten, 
Tabelle 19. Einfluß der Fermentkonzentration.

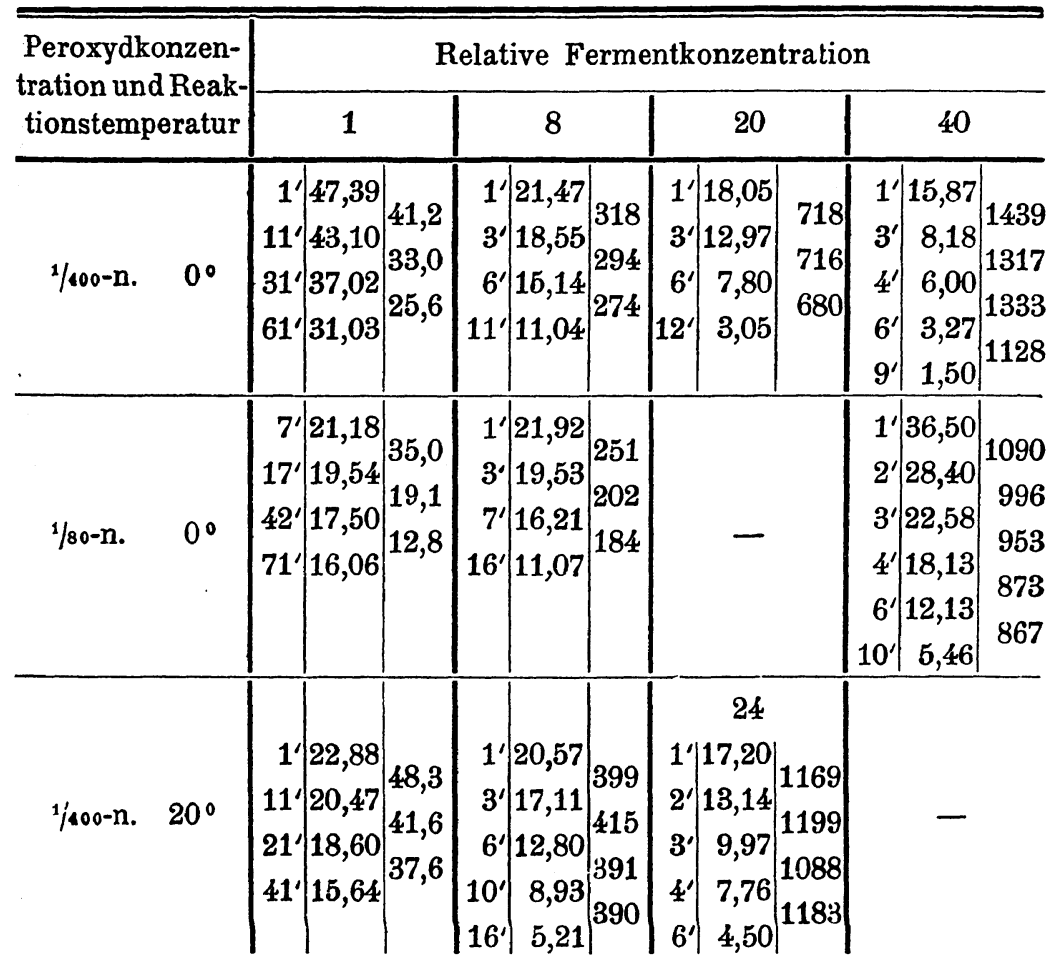

die innerhalb gleicher Phasen der Reaktion gefunden sind, so nähern wir uns sehr merklich einem wirklichen Proportionalitätsverhältnis, ja dasselbe wird sogar in Übereinstimmung mit dem Senterschen Befunde nicht selten im entgegengesetzten Sinne überschritten. Doch dürften auch diese Werte nicht ganz kommensurabel sein, da natürlich auch die Zeit der Einwirkung des gelösten Sauerstoffs auf den Grad der Adsorption von gewissem Einfluß sein wird, d. d. der langsamer sich entwickelnde Sauerstoff vollständiger von dem Ferment aufgenommen werden wird, als der sich rasch entwickelnde in den hoch konzentrierten Lösungen, bei denen ein großer Teil desselben gasförmig entweichen wird. Es ist von diesem Standpunkt aus auch durchaus begreiflich, daß bei der Temperatur von $20^{\circ}$, bei der die Adsorptionswirkung ja zurücktritt, die bessere 
Proportionalität auch bei einem Vergleich der Anfangs-K-Werte zur Beobachtung kommt.

Durch diese Sachlage entfällt natürlich auch hier die Notwendigkeit, zur Erklärung eine besondere Rührwirkung der Sauerstoffbläschen anzunehmen. Möglich ist sie trotz alledem. Man würde dann eben zu schließen haben, daß sie durch die geschilderte Adsorptionswirkung überkompensiert wird. Und ähnliches ist auch mit Bezug auf die Bedeutung der Brownschen Bewegungen zu sagen. Wir schließen uns durchaus dem Satze Senters an: "Die Partikelchen (des Ferments) selbst befinden sich in Brownscher Bewegung. Sie bewegen sich beständig in neue Flüssigkeitsteilchen hinein und bewirken dadurch, daß außerhalb der adhärierenden Schicht, durch welche die Diffusion stattfindet, eine konstante Konzentration gewahrt wird. " Jedoch erscheint es nicht erforderlich, einen Einfluß der Änderung der Brownschen Molekularbewegungen auf den Reaktionsverlauf bei Konzentrationsänderungen der Fermentlösung für die Katalase anzunehmen.

Um die Frage auf direktem Wege zu entscheiden, fehlt es an einer geeigneten Methode. Es liegt nahe, durch bestimmte Änderung der Zähigkeit der Reaktionsflüssigkeit, die nach Svedberg (vgl. Zeitschr. Elektrochem. Bd. XII, S. 853 u. 909 [1906]) dieBrownschen Bewegungen der Kolloidteilchen in bestimmbarer Weise modifiziert, und Untersuchung der Reaktionsgeschwindigkeit in solchen veränderten Lösungen den Einfluß der Brownschen Bewegung zu verfolgen. Ersteres läßt sich leicht durch Glycerinzusätze bewerkstelligen, das ein ausgezeichnetes Lösungsmittel für Katalase darstellt. Jedoch ist die Wirkung einer Zähigkeitsänderung des Reaktionsgemisches auf die Reaktionsgeschwindigkeit eines chemischen Vorgangs eine zu komplexe Erscheinung, um die gewünschte Aufklärung zu bringen.

Zunächst wird eine Änderung der Zähigkeit nämlich die Diffusion, auf die es ja hier hauptsächlich ankommt, entscheidend beeinflussen. Wenn wir also mit einer etwas modifizierten Versuchstechnik ${ }^{1}$ ) fanden, daß die in wässeriger Lösung mit einer

1) An Stelle des Permanganats muß mit Jodkali und Thiosulfat titriert werden, was bei Gegenwart von Glycerin möglich ist, wenn man sehr stark ansäuert (vgl.Ba ch, Ber.d.deutsch. chem. Gesellschaft, Bd. 38(1905), S.1882). 
bestimmten Fermentkonzentration gefundenen K-Wert 557 in $4 \%$ iger Glycerinlösung auf ca. 400 , in $8 \%$ iger auf ca. 200 , in 16\% iger auf 70 sank, ohne daß der in der wässerigen Lösung ziemlich genau nach der ersten Ordnung erfolgende Reaktionsverlauf sich änderte, so scheint, zumal sich diese Geschwindigkeitsabnahme als umkehrbar herausstellte, damit nur ein Beweis für die Richtigkeit der Diffusionstheorie erbracht zu sein,. während anderseits aus der von uns festgestellten Tatsache, daß bis zu den angeführten Glycerinkonzentrationen der Reaktionsverlauf unverändert bleibt, nur gefolgert werden könnte, daß die Brownschen Bewegungen immerhin noch ausreichten, um eine Verarmung an Peroxyd an der Diffusionsoberfläche zu verhindern.

\section{Einfluß von Säure und Alkali.}

Es bliebe nun nur noch zu erörtern, wie diejenigen Erfahrungen mit der Adsorptionstheorie in Einklang stehen, welche bei der Änderung des Hydroxyl- und Wasserstoffionengleichgewichts im Reaktionsgemisch gemacht worden sind. Es ist schon erörtert worden, daß allgemein der Kohlensäuregehalt des destillierten Wassers verzögernd auf die Reaktion wirkt, und $d a ß$ deshalb beim Übergang von kohlensäurehaltigem zu kohlensäurefreiem Wasser im Reaktionsgemisch stets eine Geschwindigkeitszunahme beobachtet wurde (vgl. Mitt. I u. II). Es ergab sich aber, daß man noch eine weitere Reaktionsbeschleunigung erzielen kann, wenn man über den Neutralitätspunkt des Wassers hinausgeht und etwa einen Hydroxylionengehalt hervorruft, der dem Farbenumschlag des Phenolphthaleins entspricht. Höherer Alkaligehalt verlangsamt dann wieder die Reaktion. Für das Platinsol ist ähnliches gefunden worden, nur daß hier das Optimum der Reaktionsgeschwindigkeit noch weiter zugunsten der Hydroxylionenkonzentration verschoben ist. Eine Erklärung hierfür kann durch die zerteilende Wirkung der Hydroxylionen auf Suspensionen gegeben werden, wodurch die wirksame Oberfläche vergrößert wird (vgl. Freundlich, Kapillarchemie, S. 384), jedoch gleichzeitig die Beständigkeit des Kolloids abnimmt. Diese Erklärung läßt sich auch durchaus auf die Fermentreaktion übertragen, nur mit dem Unterschied, daß 
offenbar hier die letztere Wirkung schneller in den Vordergrund tritt. Jedoch ist es nicht möglich, hierdurch alle Erscheinungen zu erklären, die mit einer Zunahme des Hydroxylionengehaltes verbunden sind, da nicht nur die Reaktionsgeschwindigkeit im allgemeinen, sondern auch der Reaktionsverlauf hierdurch verändert wird. Dies ist, wie schon in unserer früheren Mitteilung hervorgehoben wurde, in besonders starkem Maße beim Raupenferment der Fall. Hier ist neben der Reaktionszunahme eine ganz deutliche Verlangsamung des bei $0^{0}$ beobachteten starken Abfalls der K-Werte festzustellen. Dies hat zur Folge, $\mathrm{da} \beta$ bei einem *Dauerversuch * sich die Abnahme der $\mathrm{K}$-Werte über eine viel größere Zeit erstreckt, um dann schließlich mit einer höheren Einstellung der Werte zu enden. (Vgl. Tab. 20.)

Tabelle 20. Einfluß der Neutralisation auf den Reaktionsverlauf bei Puppenextrakten.

Deilephila euphorbiae. $\mathrm{H}_{2} \mathrm{O}_{2}-\mathrm{Konz}$. 1/400-n. $0^{\circ}$.

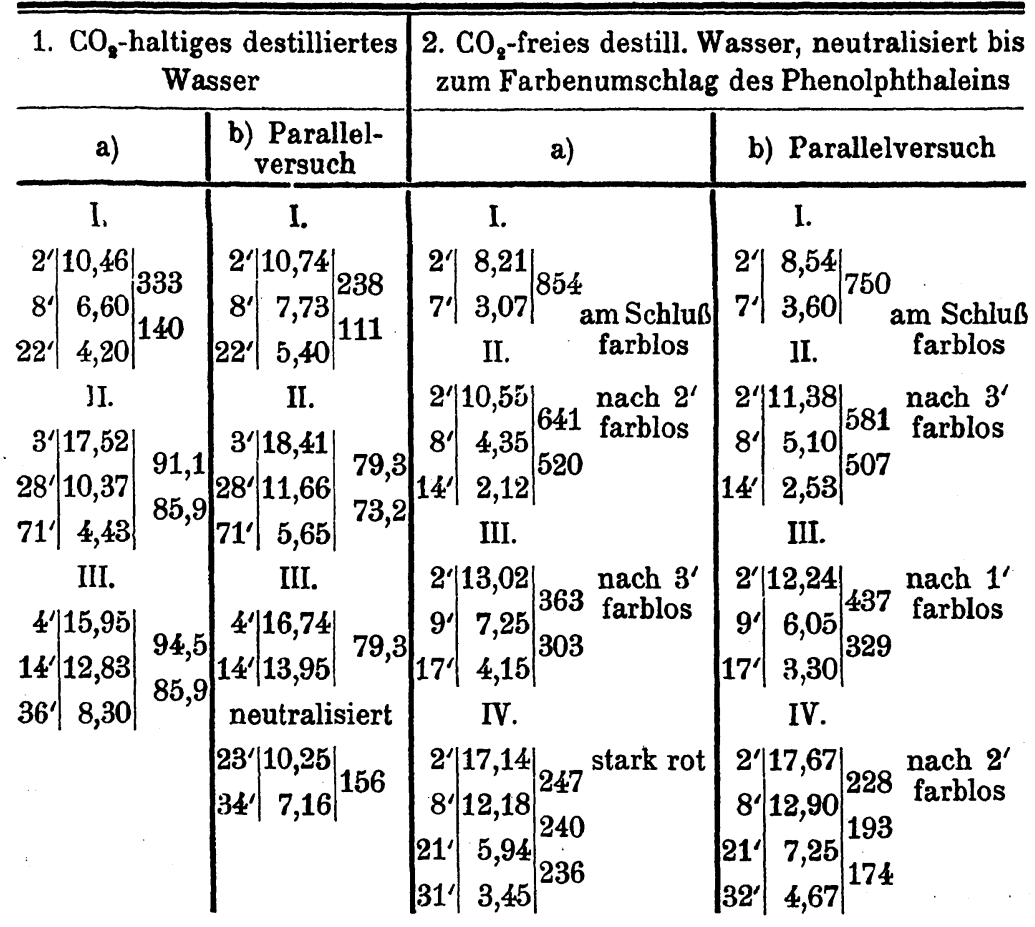


Freundlich hat die stark ansteigenden K-Werte bei der Platinkatalyse in alkalischen Lösungen durch eine Zunahme der Hydroxylionen während der Reaktion erklärt, die durch den Verbrauch des einen Teil der Hydroxylionen bindenden Peroxyds zustande käme. Das kann aber für die Fermentkatalyse nicht zutreffen. Denn wir haben während des Ablaufs der Reaktion nie eine Farbvertiefung des Indikators entsprechend einem Anwachsen der Hydroxylionenkonzentration beobachten können. Im Gegenteil, es verschwinden häufig Hydroxylionen während der Reaktion, was dadurch angezeigt wird, daß die ursprünglich durch den Indikator veranlaßte, mehr oder weniger starke Rosafärbung verschwindet (vgl. Tab. 20). Ferner wäre, wenn die Freundlichsche Erklärung auch für die Katalase zuträfe, zu erwarten, daß die Änderung des Reaktionsverlaufs unabhängig von der Fermentnatur wäre. Dies ist jedoch nicht der Fall, denn die Hämaselösungen zeigen keine deutliche Verbesserung der Konstanz der K-Werte in schwach alkalischen Lösungen.

Wie aber liegen die Verhältnisse, wenn wir auch hier die Adsorptionserscheinungen berücksichtigen? Wie bekannt, bedingen sowohl Alkalien wie Säuren tiefgreifende Änderungen des Zustandes von Eiweißsolen, was in der Änderung des kataphoretischen Wanderungssinnes, in der Beeinflussung der Aussalzbarkeit und der Hitzegerinnung deutlich hervortritt. Alle diese Eigenschaften aber stehen mit dem Adsorptionsvermögen der Sole in engem Zusammenhang. Und wenn wir die Auffassung aufrecht erhalten, daß das Adsorptionsvermögen des Ferments die Kinetik der fermentativen Hydroperoxydzersetzung entscheidend beeinflusse, so müssen Veränderungen im Alkalitätsgrade des Reaktionsgemisches hierauf ebenso einwirken wie auf die anderen genannten Eigenschaften der Eiweißsole, zu denen wir die Katalase rechnen können. Als eine Folge dieses Zusammenhangs gilt, daß ein Stoff, der in alkalischer Lösung einen anderen stark adsorbiert, in saurer Lösung diese Eigenschaft ganz verlieren kann. ${ }^{1}$ ) Wir brauchen also nur an-

S. 17 u. $20 \mathrm{ff}$.

1) Vgl. hierüber die interessanten Ausführungen von Bayliss, l. c., 
zunehmen, daß die Peroxydadsorption durch die Kolloidteilchen des Ferments je nach dem Überschuß an Hydroxyl- oder Wasserstoffionen gefördert bezw. verringert wird, um eine Erklärung für die Reaktionsbeschleunigung bezw. Reaktionsverzögerung zu erhalten. Diese Auffassung deckt sich auch durchaus mit der Reversibilität der Säure- und Alkaliwirkung. Wenn wir aber annehmen, daß das Absorbens sich in merklicher Weise ändert, so ist es ohne weiteres verständlich, daß nicht nur die Reaktionsgeschwindigkeit, sondern im allgemeinen auch der Reaktionsverlauf durch diese Änderung modifiziert werden kann, da in der Gleichung

$$
-\frac{\mathrm{dc}}{\mathrm{dt}}=\mathrm{k}^{\mathrm{t}} \cdot \alpha \cdot \mathrm{c}^{\frac{1}{\mathrm{n}}}
$$

nicht nur $\alpha$, sondern auch die den Reaktionsverlauf bestimmende Größe $\frac{1}{\mathbf{n}}$ verändert sein kann.

Natürlich kann auch die von Freundlich gegebene Erklärung der Aktivitätszunahme durch VergröBerung des Zerteilungsgrades in Betracht kommen, ${ }^{1}$ ) eine Erscheinung, der dann zur Erklärung der Säurewirkung ein Zusammentreten der Teilchen zu größeren Komplexen entsprechen würde. Und in der Tat ist von uns häufig eine Trübung des Reaktionsgemisches bei Säurezusatz zu der vorher klaren Lösung beobachtet worden. Jedoch scheint es geboten, gerade solchen Erscheinungen nicht zuviel Gewicht beizulegen, denn die häufig in den konzentrierten Fermentlösungen eintretenden spontanen, und durch Verdünnung veranlaßten Trübungen lassen, wie früher dargelegt, auf den Reaktionsverlauf und die Aktivität des Ferments keinen Einfluß erkennen, hängen also offenbar nicht mit einer Veränderung der aktiven Substanz selbst zusammen.

Endlich ist natürlich, wenn man die Eiweißnatur der Katalase postuliert, die jedoch ja noch keineswegs sichergestellt ist, mit Rücksicht auf die Wirkung von Säure und Alkali an

1) Vgl. hierüber auch Bredig, Diese Zeitschrift, Bd. 31, S. 306 (1899) und H. J. S. S and, Diese Zeitschrift, Bd. 51, S. 642 ff. (1905). 
die amphotere Natur dieser Stoffe zu denken. ${ }^{1}$ ) Stellen wir uns vor, daß der amphotere Stoff das aktive Kolloid darstelle, das durch Salzbildung in ein negatives bezw. positives inaktives Ion übergeführt werden kann, so ist klar, daß derjenige $\mathrm{Zu}$ stand der Lösung die größte Aktivität des Ferments ergeben muß, bei dem am meisten von dem unionisierten amphoteren Kolloid existenzfähig ist. Sowohl der Zusatz von Säure als der von Basen wird eine Abnahme des reinen Kolloids zugunsten der inaktiven, in echter Lösung vorhandenen Ionen zur Folge haben und damit zu einer Schwächung der Aktivität der Lösung führen. Da jedoch bei der Katalase das Optimum der Reaktionsgeschwindigkeit nach einem geringen Hydroxylionenüberschuß verschoben ist, so würde man, vorausgesetzt, daß im übrigen die gemachten Annahmen zutreffen, sich vorzustellen haben, daß die basischen Eigenschaften des Kolloids gegenüber den sauren überwiegen. Wie aber schon hervorgehoben, sind alle diese Erklärungen, welche auf eine Deutung der Aktivitätsabnahme durch eine Verminderung der Teilchenzahl hinauslaufen, nicht geeignet, die Veränderung des Reaktionsverlaufs, welche mit einer Vermehrung der Hydroxylionen verbunden ist, zu erklären. Hierzu bleibt es erforderlich, eine Veränderung des Adsorptionsvermögens der Teilchen anzunehmen, welche sehr wahrscheinlich in dem vorhin erörterten Sinne stattinden kann.

\section{Die Pilzkatalase.}

Zum Schlusse sei noch ein kurzes Wort darüber gesagt, wie sich die anderen Fermente dem besprochenen Verhalten anpassen. Im ganzen läßt sich sagen, daß sich auch bei diesen Fermenten (aus Fett, aus Leber, aus den Geschlechtsorganen von Fröschen u. s. w.) das Verhalten ungezwungen durch die beschriebenen Eigenschaften der Blut- und Raupenfermentlösung erklären läßt. Auch bei diesen Fermenten wird fast immer ein absteigender Gang der K-Werte beobachtet, der durch Varia-

1) Vgl. hierzu die Befunde Sackurs am Casein, Diese Zeitschrift, Bd. 41, S. 672 (1902). 
tion der Peroxydkonzentration, der Temperatur, der Fermentkonzentration in der zu erwartenden Weise beeinflußt wird. Nur das Verhalten des sehr aktiven Preßsaftes, der aus Pilzen gewonnen werden kann, scheint zunächst abweichend zu sein. Denn untersucht man hier den Temperatureinfluß, so ist, wie schon in der früheren Mitteilung betont wurde, eine ganz auffällige Temperaturwirkung festzustellen derart, daß der Abfall der K-Werte anstatt bei höherer Temperatur geringer zu werden, eine ganz abnorme Zunahme zeigt. Auch hier kann von einer Oxydation des Ferments durch das Peroxyd keine Rede sein, denn gerade dieses Ferment zeigt eine ganz besonders große Unempfindlichkeit gegen Erhöhung der Peroxydkonzentration (siehe frühere Mitteilung. ${ }^{1}$ ) Das abweichende Verhalten findet aber eine einfache Erklärung in der abnormen Labilität der frischen Pilzextrakte überhaupt, die durch geringe Temperaturerhöhung außerordentlich gesteigert wird. Setzt man den Saft nach dem Auspressen der Wirkung der Zimmertemperatur aus, so führt das meist in kurzer Zeit zu völliger Inaktivierung des Saftes. Bei $0^{0}$ nimmt die Aktivität des unverdünnten Saftes meist auch langsamer oder schneller ab, bleibt jedoch nach einiger Zeit auf einer bestimmten Höhe und in diesem Stadium paßt sich dann die Fermentlösung in ihren kinetischen Eigenschaften besser dem Verhalten des Blutferments an. Der Gang bei $0^{0}$ ist fast verschwunden und die Erhöhung der Temperatur bringt keine Steigerung des Ganges mehr hervor. Von Apple$\mathrm{man}^{2}$ ) ist eine ähnliche Emfindlichkeit des äktiven Stoffes aus Kartoffeln festgestellt worden und er hat diese auf eine inaktivierende Wirkung der beim Zerreiben und Auspressen der Kartoffeln in den Saft übergehenden pflanzlichen Säuren zurückgeführt. Es gelang ihm dadurch, daß er den Saft unter Zusatz von Calciumcarbonat auspreßte, die Schwächung zu vermeiden. Die schwach saure Reaktion, welche der Pilzsaft besitzt, kann jedoch bei diesem schwerlich die Ursache für die Empfindlichkeit desselben sein. Denn auch wenn man den Saft beim Auspressen direkt über gefälltem Calciumcarbonat auffängt, zeigt

1) l. c., S. 203.

2) Botanical Gazette, Bd. 50, S. 182 (1910). 
er den starken Aktivitätsrückgang, besonders wenn man die Fermentlösung in verdünntem Zustande stehen läßt. Über die Ursache der Labilität des Pilzsaftes läßt sich von vornherein also nichts sagen. Sie ist jedenfalls identisch mit der auch bei anderen Fermenten, wenn auch in viel schwächerem Maße auftretenden spontanen Aktivitätsabnahme beim Stehen, besonders bei höherer Temperatur. Der Umstand, daß der Verdünnungsgrad der Fermentlösung von wesentlichem Einfluß auf die Geschwindigkeit ist, mit der sich die Schwächung vollzieht, spricht ebenso wie der sprungweise und unregelmäßige Verlauf der Erscheinung dafür, daß es sich um eine Änderung des kolloidalen Zustandes des aktiven Stoffes handelt. Mit der in der Hauptsache wohl durch die vorhandene Tyrosinase verursachten Färbung und Niederschlagsbildung in den Säften hat jedoch diese Schwächung nichts zu tun. Die Empfindlichkeit ist nicht bei allen Säften gleich groß, aber übertrifft immer diejenige anderer Katalasen sehr bedeutend. Eine Ähnlichkeit mit dem Raupenferment besteht insofern, als hier wie dort starke Aktivität und starke Labilität zusammengehen. Bei dem Raupenferment ist beides verursacht durch besonders starkes Adsorptionsvermögen. Es ist durchaus nicht unmöglich, daß die Verhältnisse bei den Pilzsäften ähnlich liegen. Der Aktivitätsabnahme liegt keine eigentliche Zerstörung, beruhend auf einer chemischen Reaktion, sondern eine bloße physikalische Zustandsänderung zugrunde, die wir auch hier am besten durch eine Änderung des Adsorptionsvermögens erklären werden, die sehr wohl durch die beim Auspressen zu der Katalase tretenden Fremdstoffe mit veranlaßt sein kann. Die Herstellung einer aktiven Fällung aus Pilzsaft ist uns bisher leider nicht geglückt. Mit Sicherheit geht jedenfalls aus unseren auch mit diesem Ferment angestellten zahlreichen Versuchen hervor, daß bei näherer Betrachtung das Verhalten der Pilzkatalase nicht mit den erörterten Anschauungen in Widerspruch steht.

Kurze Zusammenfassung und Schluß.

Die Annahmen Senters zur Erklärung der Abweichungen im Verhalten der fermentativen Hydroperoxydzersetzung von 
dem Schema einer Reaktion I. Ordnung beruhend auf bestimmten Vorstellungen über Beeinflussung des Diffusionsvorganges durch die gebildeten Sauerstoffbläschen und die Brownschen Bewegungen der Fermentteilchen und über die Oxydierbarkeit des Ferments durch Hydroperoxyd sind ungeeignet, die tatsächlich beobachteten Abweichungen zu erklären.

Dagegen lassen sich die Eigentümlichkeiten des Reaktionsverlaufs ebenso wie die Eigenschaften der Fermentlösungen überhaupt hinreichend erklären, wenn man den durch die große Oberflächenentwicklung der kolloidalen Fermentteilchen bedingten Ad s or ptionsv org äng en Rechnung trägt, diesich sowohl auf den reagierenden Stoff $\left(\mathrm{H}_{2} \mathrm{O}_{2}\right)$ wie auf das Reaktionsprodukt $\left(\mathrm{O}_{2}\right)$, endlich aber auch auf zufällig vorhandene oder künstlich zum Reaktionsgemisch zugesetzte Fremdstoffe erstrecken können.

Dann ist jedoch ein Ablauf der Reaktion nach dem Schema I. Ordnung überhaupt nicht mehr zu erwarten, dann behält man die Ansicht bei, daß die gemessene Reaktionsgeschwindigkeit diejenige eines Diffusionsvorganges ist, während der eigentliche chemische Zerfall des Peroxyds sich mit nicht meßbarer Geschwindigkeit an der Oberfläche der Kolloidteilchen vollzieht, wofür von Senter mit Recht die im Vergleich mit anderen Fermentvorgängen außerordentlich geringe Beeinflussung der Reaktionsgeschwindigkeit durch die Temperatur angeführt wird, so wird eine Adsorption des Peroxyds an der Oberfläche des Kolloids infolge der hiermit verbundenen Konzentrationserhöhung einen schnelleren Ablauf der Reaktion, d. h. eine Zunahme der nach der Reaktion I. Ordnung berechneten K-Werte (vgl. S. 470) zur Folge haben.

Tritt hierzu jedoch noch die Adsorption des sich bei der Reaktion entwickelnden Sauerstoffs, so erscheint die Annahme berechtigt, dạß diese entweder durch Adsorptionsverdrängung oder durch die Bildung einer für das Peroxyd schwerer diffusiblen Schicht die Reaktion verzögern wird (vgl. S. 471).

Hiernach wird aber eine annähernde Konstanz der K-Werte, wie eine einfache Überlegung ergibt, nur dann als Grenzfall eintreten, wenn sich die beiden einander entgegengesetzten Wirkungen gerade kompensieren. Unter den bisher angewen-

Hoppe-Seyler's Zeitschrift f. physiol. Chemie. LXXIX. 
deten Versuchsbedingungen ist dies im allgemeinen jedoch nicht der Fall: Hier tritt infolge der Anhäufung des Sauerstoffs in der Lösung notwendig eine Reaktionsverzögerung ein, die sich in einem Abfall der nach der I. Ordnung berechneten K-Werte zu erkennen gibt. Dieser Gang der K-Werte wird bei längerer Versuchsdauer mit der Annäherung an das durch die Sättigung des Reaktionsgemisches mit Sauerstoff sich ausbildende Adsorptionsgleichgewicht verschwinden, indem nun die Reaktion nur noch, im ganzen mit wesentlich geringerer Geschwindigkeit verlaufend, von der jeweiligen Peroxydkonzentration in dem oben ausgeführten Sinne abhängig sein wird.

Der in sehr zahlreichen Beispielen mit Fermenten verschiedener Herkunft.und verschiedenen Reinheitsgrades verfolgte Reaktionsverlauf der fermentativen Hydroperoxydzersetzung entspricht diesen Annahmen durchaus. Insbesondere erweisen die Versuche über den Einfluß von Temperatur, von Peroxydkonzentration und Fermentkonzentration, von Zusätzen von Säure und Alkali, besonders auch der Anwesenheit von $\mathrm{CO}_{2}$, die Brauchbarkeit der theoretischen Annahme.

Der eigentümliche und sonst kaum deutbare Einfluß der Temperatur auf die Reaktion, der in einer nur sehr geringen Zunahme der Reaktionsgeschwindigkeit, aber einer ganz auffallenden Änderung des Reaktionsverlaufes besteht, kann einfach durch die Berücksichtigung der Adsorptionsrorgänge erklärt werden.

Die bei Erhöhung der Peroxydkonzentration eintretende Abnahme der Reaktionsgeschwindigkeit ergibt sich aus der dabei zu erwartenden stärkeren Sauerstoffadsorption durch das Ferment und der daraus folgenden stärkeren Beeinträchtigung des Diffusionsvorganges.

Auch die fast immer beobachtete Empfindlichkeit der Fermentlösungen, welche sich in einem scheinbar spontanen (Altern) oder durch äußerst geringe Veränderungen (Verdünnung, geringe Änderung der Alkalität) hervorgerufenen mehr oder weniger raschen Aktivitätsrückgang zu erkennen gibt, erklärt sich besser, wenn man als aktivitätsbeeinflussenden Faktor das Adsorptionsvermögen des Fermentes einführt, welches sich 
in seinem Betrage von sehr geringen Einflüssen abhängig denken läßt.

Die Sauerstoffadsorption durch die Fermentlösung und ihr Einfluß auf den Reaktionsverlauf ist durch die folgenden Tatsachen erwiesen:

1. Hebt man durch Schütteln die während der Reaktion auftretende Sauerstoffübersättigung auf, so wächst die Reaktionsgeschwindigkeit.

2. Die Wirkung ist weit erheblicher und gibt $\mathrm{zu}$ einer völligen Veränderung des Reaktionsverlaufs Anlaß (Aufsteigender Gang der nach I. Ordnung berechneten K-Werte), wenn das Schütteln im Vakuum erfolgt.

3. Dagegen bedingt Sättigung der Fermentlösung mit Sauerstoff vor der Reaktion eine erhebliche Abnahme der Reaktionsgeschwindigkeit unter gleichzeitiger Änderung des Reaktionsverlaufs in dem zu erwartenden Sinne (bessere Konstanz der K-Werte).

4. Gasvolumetrische Versuche ergeben,

a) daß die Übersättigung mit Sauerstoff in der Fermentlösung um so größer ist und sich durch Rühren um so schwerer beseitigen läßt, je größer die Fermentkonzentration ist;

b) daß der gasvolumetrisch verfolgte Reaktionsverlauf bei der Fermentkatalyse des Hydroperoxyds (kolloidale Lösung des Katalysators) gegenüber der Jodionenkatalyse des Hydroperoxyds (echte Lösung des Katalysators) die zu erwartenden Unterschiede hinsichtlich des Einflusses von Vorbehandlung mit Sauerstoff und Rührwirkung erkennen läßt.

Die Untersuchung wird fortgesetzt. 